\title{
NUEVAS ESTRATEGIAS DE DIGITALIZACIÓN DENTRO DEL MEGALITISMO CANTÁBRICO: MODELOS 3D, VISITAS Y APROXIMACIONES VIRTUALES DEL PROYECTO DE LA COBERTORIA (SALAS, ASTURIAS)
}

\section{A STRATEGIC MOVE FOR DIGITIZING THE CANTABRIAN MEGALITHISM: 3D MODELS, VIRTUAL TOURS AND APPROACHINGS TO THE NECROPOLISES DEVELOPED BY THE COBERTORIA'S PROJECT (SALAS, ASTURIAS)}

Fernando R. del Cuetoํ, Miguel Busto Zapico², Daniel Herrera Arenas³, Silverio García Cortés ${ }^{4}$, Carlos García-Noriega Villa ${ }^{5}$

Recibido: 09/05/2021 - Aceptado: 30/07/2021

DOI: https://dx.doi.org/10.5944/etfi.14.2021.30819

\section{Resumen}

El presente texto sintetiza las novedosas metodologías de registro, así como el modo de elaboración de materiales de divulgación, puestos en marcha en el proyecto de la Cobertoria, orientado al estudio de los paisajes megalíticos del área centrooccidental asturiana. Las dos líneas de trabajo preferentes son, en la actualidad, la excavación de sitios de especial interés, como el dolmen de la Cobertoria, y la actualización del catálogo de túmulos prehistóricos de todo el concejo de Salas. Durante la primera, se reunió un registro tridimensional a través de técnicas fotogramétricas y se realizaron dos vuelos de dron sobre la estructura megalítica, en 2016 y 20I9, que permitieron el montaje de varios modelos 3D que ya están disponibles en web. Además, dos aproximaciones y dos visitas (ambas virtuales) a las necrópolis de San Juan y Penausén completan el lote de materiales empleados para el análisis del paisaje arqueológico, sirviendo también de itinerarios virtuales por estos lugares.

\footnotetext{
1. Área de Prehistoria. Departamento de Historia. Universidad de Oviedo. Facultad de Filosofía y letras. Campus del Milán. c/ Amparo Pedregal s/n, 33011, Oviedo, rodriguezcfernando@uniovi.es

2. Juan de la Cierva-Formación. Departamento de Historia Medieval y Ciencias y Técnicas Historiográficas. Universidad de Granada, bustomiguel@ugr.es

3. Observatorio del territorio. Departamento de Geografía. Universidad de Oviedo. Facultad de Filosofía y letras. Campus del Milán. c/ Amparo Pedregal s/n, 33011, Oviedo, daniel@observatoriodelterritorio.es

4. Área de Ingeniería Cartográfica. Escuela Politécnica de Mieres. c/Gonzalo Gutiérrez Quirós s/n, 33600 Mieres, Asturias, sgcortes@uniovi.es

5. Arqueólogo independiente, carlosgarnor@gmail.com
} 
Palabras clave

Neolítico; fotogrametría; fotografía aérea; Photoscan; Prehistoria reciente

\section{Abstract}

This paper reports on the main methodological aspects developed during the Cobertoria's Project, which aims to study the architecture and the landscapes linked with the prehistoric barrows in mid-western Asturias. The two main lines of the project are focused on digging remarkable sites (Cobertoria's dolmen), as well as in updating the Sites and Monuments Record of Salas council. Regarding excavations, the archaeological record gathered in the dolmen of the Cobertoria allowed us to do several 3D photogrammetries. Two drone flights were developed over the tumulus for taking information in the two main stages of the excavations. As a result, several 3D models of different parts of the excavated area are accesible now on the web for purposes of interpretation and research. Finally, two virtual tours and two approachings to the necropolises are already available as part of a broader analysis of the landscape.

Keywords

Neolithic; photogrammetry; aerial photography; Photoscan; late Prehistory 


\section{INTRODUCCIÓN: EL PROYECTO DE LA COBERTORIA}

El proyecto de la Cobertoria arranca gracias al interés de la Fundación ValdésSalas en la investigación, conservación y divulgación del patrimonio megalítico conservado en el concejo de Salas, dentro de la comarca centro-occidental asturiana (Figura I). Gracias a esta entidad se pudo recibir el apoyo de la Fundación Banco Sabadell y del Ayuntamiento de Salas, que también colaboraron con nuestro trabajo. El empeño en tales actividades encaja con los propósitos de la fundación, y es parte esencial del programa de la extensión universitaria de la Universidad de Oviedo (Friera 20I6). Por eso, la renovación y la difusión de los conocimientos, a diferentes espacios geográficos y grupos de población, son claves también en un proyecto que comenzó en 2016 por lo que transcurre ya en su quinto año de andadura ${ }^{6}$.

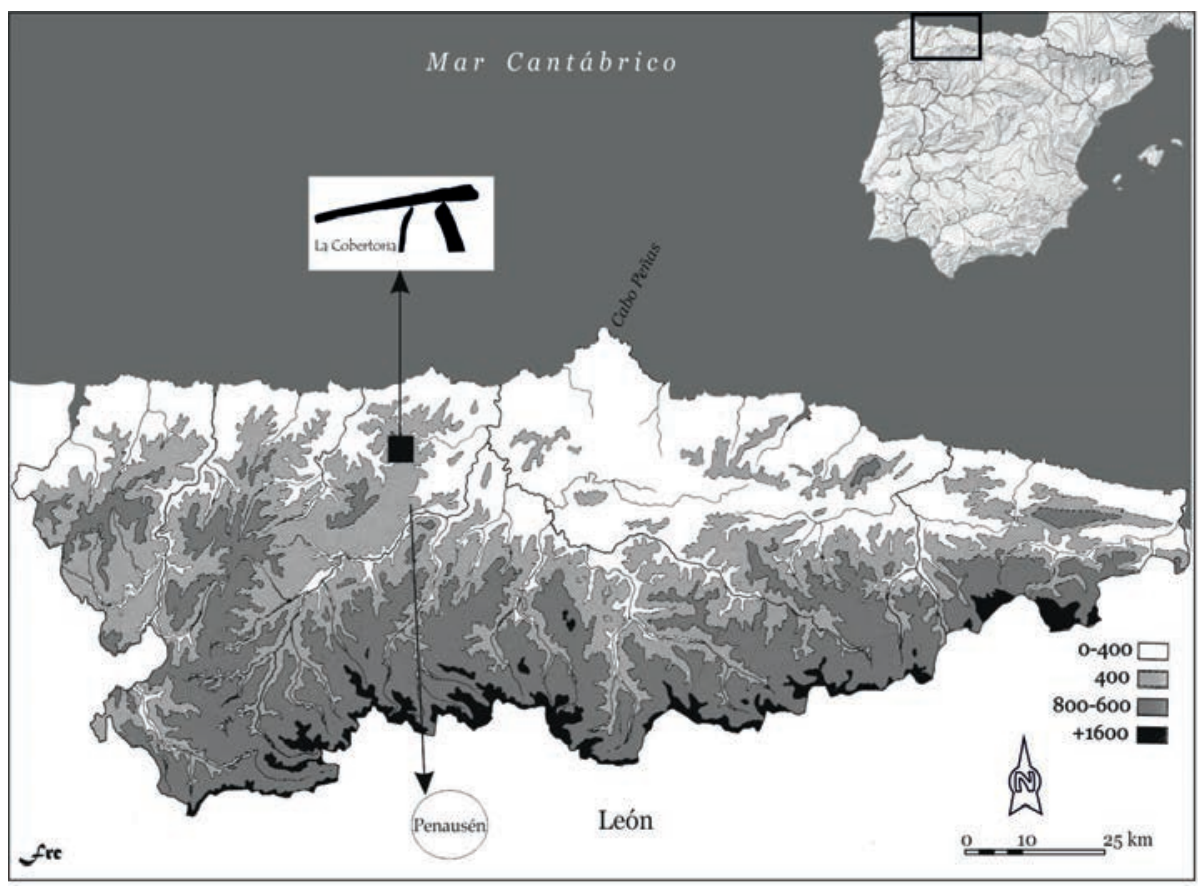

FIGURA 1. MAPA DE LA REGIÓN CON LA INDICACIÓN DE LAS DOS NECROPOLIS TUMULARES TRATADAS EN EL TEXTO

La estrategia de concentrarse en estos yacimientos arqueológicos no es únicamente científica pues, a pesar de su antigüedad e importancia histórica, los megalitos asturianos suelen ser bastante olvidados dentro del patrimonio regional. Por esa razón nuestro plan debe ser forzosamente ambicioso, al tener como fin último que los megalitos puedan recuperarse (o potenciarse aún más) como lugares de referencia, en clave paisajística e histórica, en su espacio inmediato. Quizá la única manera de generar una protección real, efectiva y asumible económicamente para

6. Los contenidos de geografía de este trabajo forman parte también de la difusión de resultados del proyecto de investigación I+D titulado «La realidad aumentada como herramienta para la explicación de paisaje. Aplicaciones a la docencia y al turismo (CSO2017-84623-R)» del Ministerio de Economía, Industria y Competitividad. 
estos frágiles testimonios funerarios, inmersos en boscosos territorios de montaña apartados de la mirada y del control de la mayoría de la población.

El primer paso para conseguir esos ambiciosos objetivos es desarrollar un balance preciso con el que identificar cuál es el estado actual de cada una de las necrópolis del concejo. No olvidemos que el inventario arqueológico de Salas fue realizado hace treinta años y en ese tiempo las zonas arqueológicas sufrieron gran cantidad de agresiones y afecciones menores. A partir de la revisión del corpus arqueológico se pueden establecer las prioridades y necesidades que tiene cada conjunto, tanto en lo tocante a su investigación como en su conservación.

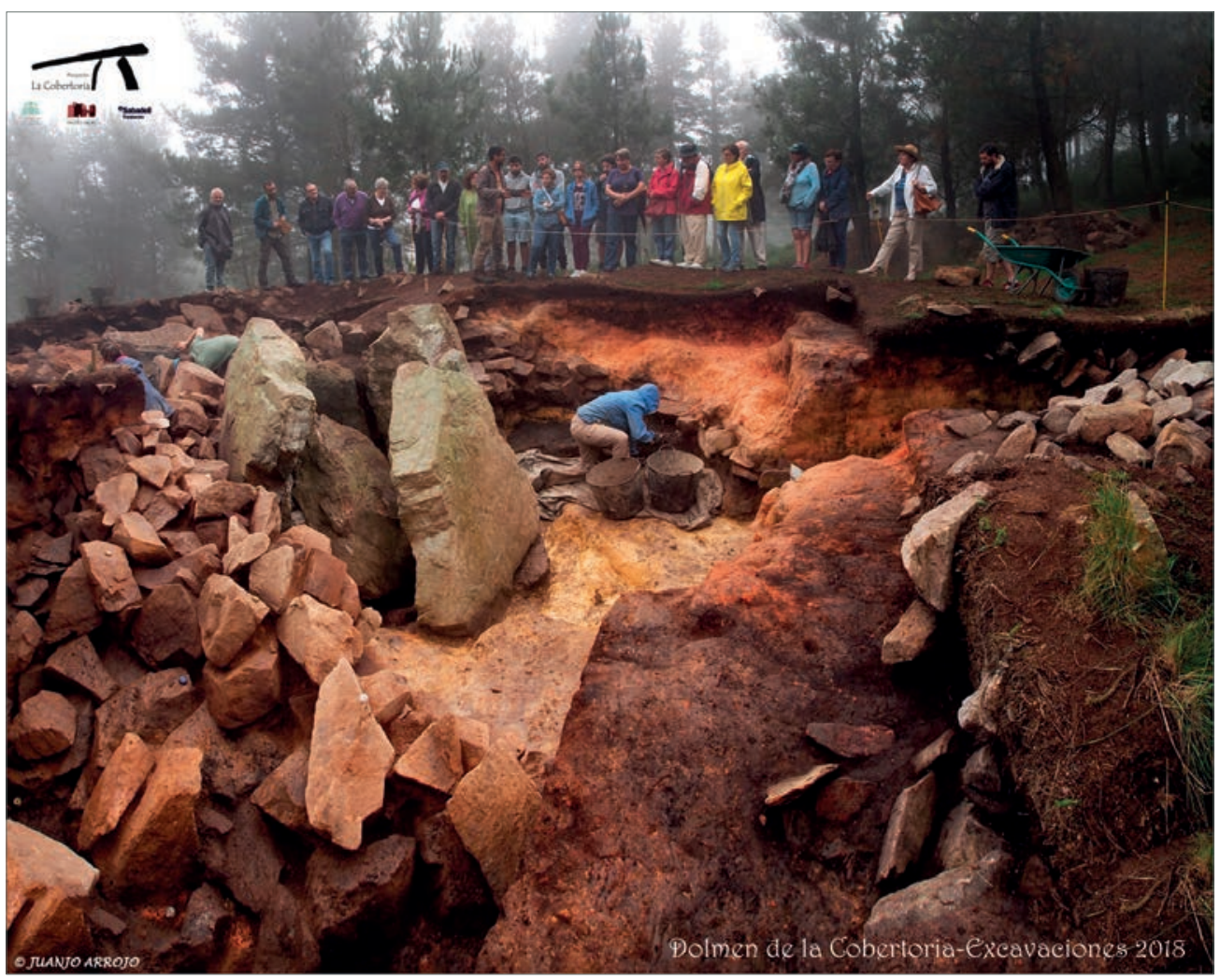

FIGURA 2. JORNADA DE PUERTAS ABIERTAS, DURANTE LOS TRABAJOS DE CAMPO DE 2O18, EN EL DOLMEN DE LA COBERTORIA

Asimismo, tanto la Fundación Valdés-Salas como el área de Prehistoria de la Universidad de Oviedo están intentando aprovechar las experiencias formativas que tiene la arqueología de campo. Aunque en 2016 arrancamos con un modestísimo equipo, durante los últimos tres años colaboraron con el proyecto un número respetable de estudiantes nacionales e internacionales de grado (o máster) en Arqueología, Historia y Prehistoria (Figura 2). Dentro de nuestra rutina diaria, y también en la formación de nuevas generaciones de profesionales de la arqueología, deben estar siempre presentes las últimas técnicas de documentación y, por ese motivo, los registros tridimensionales se sumaron a los documentos de excavación habituales: unidades estratigráficas, topografías, dibujos de campo, diarios, etcétera. La apuesta por reunir un registro paralelo de modelos tridimensionales ha sido clara y por esa razón tuvieron el mismo 
trato que dibujos y topografías. Siempre preferimos disponer de un mayor legado digital, ya que una excavación más extensa (o más rápida) no es por sí sola garantía de que el trabajo esté mejor hecho, como cualquier manual de campo indica en sus capítulos más introductorios (Burke y Smith 2004: II7).

Junto a la novedad de las técnicas debe remarcarse que todas las personas e instituciones implicadas en el proyecto están haciendo importantes esfuerzos por dar a conocer la información recuperada, tanto en textos y reuniones destinados a especialistas (R. del Cueto y Blas 2018; R. del Cueto y Busto 2020; R. del Cueto y Carrero 202I), como en otras plataformas y entornos fuera del ámbito académico. En la página de la fundación ${ }^{7}$, por ejemplo, se describen algunas de las necrópolis revisadas, así como toda la información derivada del proyecto. A nivel vecinal también colaboramos con la Asociación de vecinos de San Pedro de Mallecina, pueblo cercano al dolmen de la Cobertoria. Un vínculo que permitió aprovechar la recién restaurada escuela de niños local para alojar una exposición temporal sobre el megalitismo en Salas.

El presente texto trata de compendiar y dar a conocer las apuestas del proyecto por una forma de trabajo que permitió elaborar un amplio conjunto de recursos digitales ya disponibles en red. La investigación desarrollada estos años fue esencial para, a partir de ella, preparar materiales que no solo sirvieran para acumular más información, sino para que también pudieran ser empleados en tareas de una divulgación arqueológica más cercana y directa. Lo ya hecho no hubiera sido posible sin el buen hacer y el altruismo de muchas personas de distintas ramas de conocimiento, que son parte de un proyecto, el de la Cobertoria, que consiguió implicar departamentos de la Universidad de Oviedo tan heterogéneos como los de Historia, Geografía o Ingeniería.

\section{REGISTROS ARQUEOLÓGICOS DEL PROYECTO DE LA COBERTORIA: BASES DE INFORMACIÓN PARA EL 3D Y LOS RECORRIDOS VIRTUALES}

El dolmen de la Cobertoria, yacimiento que da nombre al proyecto, forma parte de un cementerio más extenso que contaba, en los años 70, con once estructuras y que cristalizó en la bibliografía arqueológica como necrópolis de la sierra de San Juan (Figura 3). Su descubrimiento se lo debemos a J. M. González, el primero que documenta y publica los restos como parte de su extenso catálogo de sitios prehistóricos (I973: 27). En años posteriores M. A. de Blas visitará, durante la preparación de su tesis doctoral, el monumento y documentará la superficie de la cámara funeraria, sus ortostatos, así como el túmulo que recubría las estructuras (I983: 55). Como muchos otros, la Cobertoria había sido expoliada con intensidad, generando múltiples cráteres en la zona superior del túmulo que dejaron a la vista también su área central.

7. Para más información, se puede acudir a la siguiente dirección: http://fundacionvaldessalas.es/ proyecto-la-cobertorial 


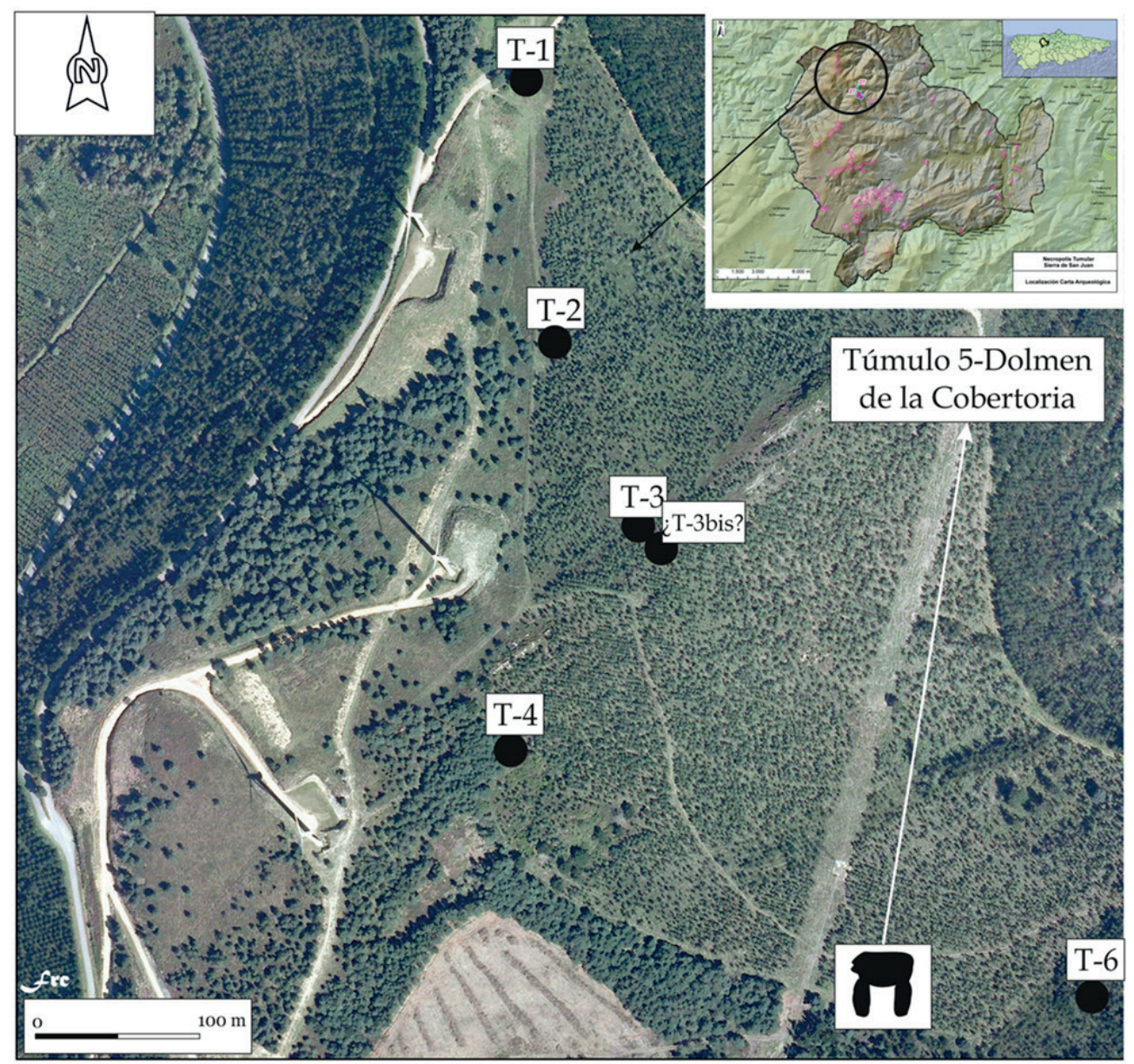

FIGUURA 3. ORTOFOTOGRAFÍA CON LOS TÚMULOS PRESENTES EN LA NECRÓPOLIS DE LA SIERRA DE SAN JUAN

A partir del año I990, y como parte de la política de reconocer y catalogar los yacimientos existentes en cada concejo, la Cobertoria será incluida en el inventario regional con el erróneo nombre de la Campa San Juan ${ }^{8}$. Durante los años previos a la realización de la carta las actividades forestales que se estaban realizando en la zona eran ya abundantes, y los daños que producían por aquel entonces al patrimonio aún resultaban difíciles de controlar. Quizá por eso de los once sitios localizados inicialmente, dos décadas después solo quedaban seis elementos (R. del Cueto y Carrero 202I: I4-I6).

Además de la sierra de San Juan y del dolmen de la Cobertoria las visitas virtuales comprendieron también la necrópolis de Penausén, ubicada entre las localidades de La Bouga y el Pevidal y dentro del cuadrante suroccidental del concejo de Salas. Este lugar también fue identificado por J. M. González en el año I970 (I973). En ese momento el conjunto estaba formado por doce tumbas distribuidas en dos ejes:

8. En realidad, la Campa San Juan se encuentra por debajo en altura de la Cobertoria, en una llanada que separa la necrópolis de las Corradas de la de San Juan. 
uno NNE-SSW, que aglutina el conjunto principal con cinco estructuras (de Blas I978; I980); mientras que las siete restantes jalonan un eje de clara alineación E-W (túmulos 6 a I2) (Figura 4).

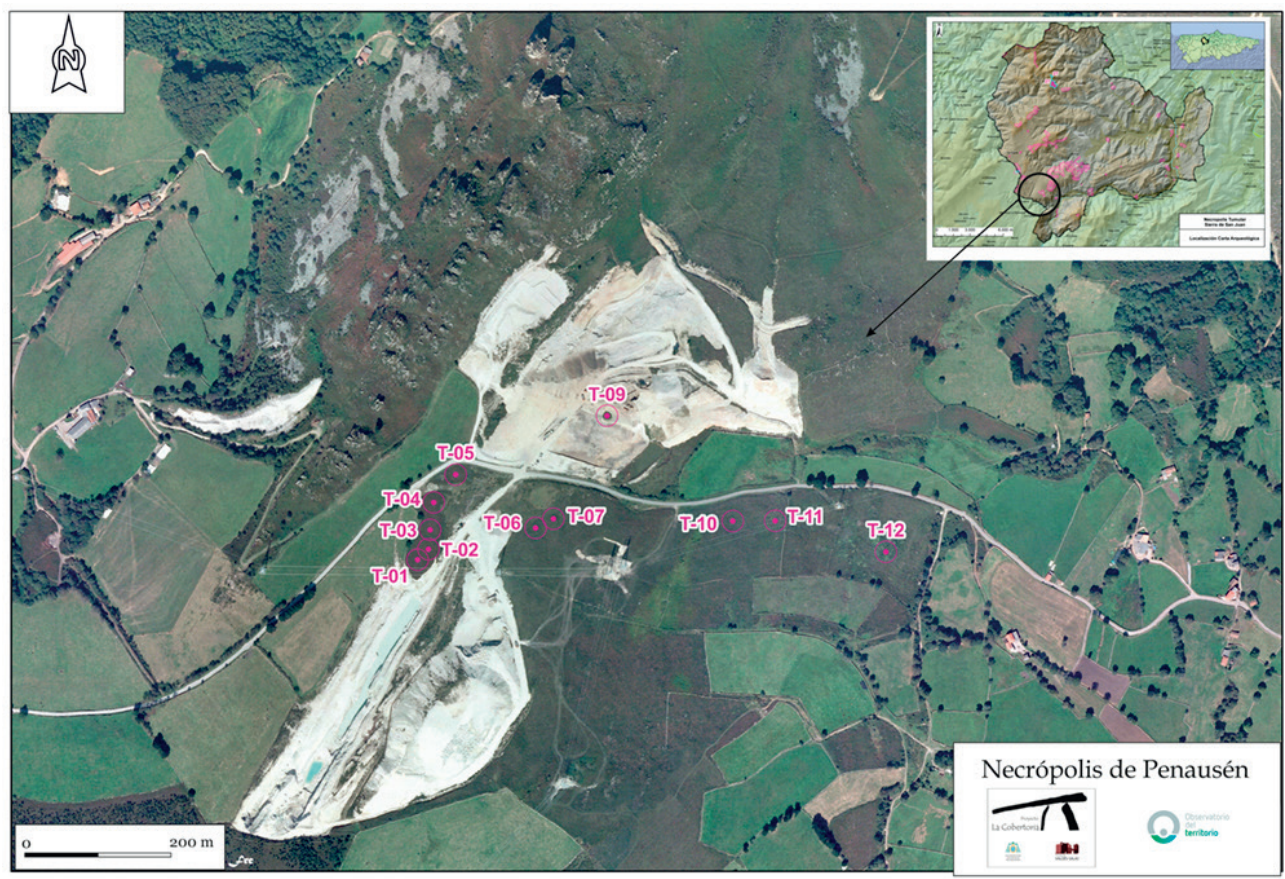

FIGURA 4. ORTOFOTOGRAFÍA CON LOS TÚMULOS PRESENTES EN LA NECRÓPOLIS DE PENAUSÉN

En cuanto a los resultados de las excavaciones del dolmen de la Cobertoria, hemos de indicar que estas indagaciones analizan un tipo megalítico relativamente escaso (al menos en número) en la cornisa Cantábrica, como son los dólmenes de corredor. También están mostrando que, en el espacio construido en la Prehistoria, se produjeron cambios y reedificaciones durante al menos quinientos años, un proceso que no es exclusivo de la Cobertoria, pues está ocurriendo en otros muchos megalitos del noroeste peninsular como puede ser el caso de Forno dos Mouros, entre otros muchos (Mañana, 2005). No es extraña por tanto la cada vez mayor concordancia entre registros arqueológicos y aquellas consideraciones que hacen hincapié en las largas biografías de los túmulos (Mañana, 2003; Tejedor, 2014). En el caso salense las ampliaciones también parecen demostrar la especial trascendencia de este lugar, con una apuesta muy clara por la mejora del marco arquitectónico tras el que seguramente se esconden ceremoniales y enterramientos (Figura 5). Las diferentes mudas de la fisionomía tumular nos están conduciendo a un proceso cargado de hiatos y en el que hemos diferenciado tres fases prehistóricas, a las que debemos sumar varios accesos a la ruina en momentos históricos más recientes. 


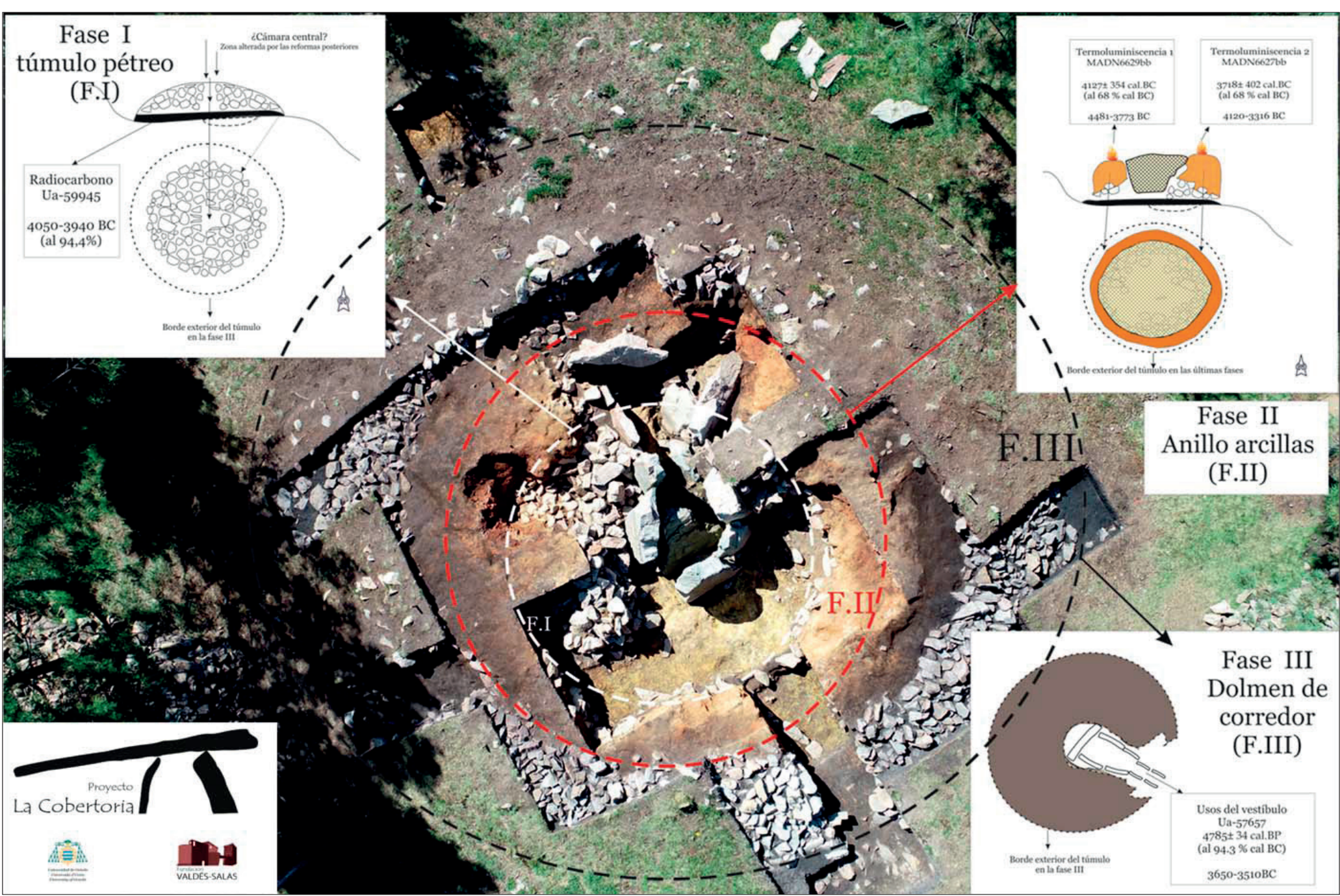

FIGURA 5. SÍNTESIS DE LAS TRES FASES CONSTRUCTIVAS PRESENTES EN EL DOLMEN DE LA COBERTORIA

(4000-3500 A. C.)

\subsection{PRIMERA FASE}

Los momentos constructivos prehistóricos que hemos identificado se extienden a lo largo de una banda temporal de cinco siglos y fueron realizados en lo que podríamos considerar un tiempo clave en el megalitismo cantábrico. Las evidencias más antiguas recuperadas hasta el momento nos retrotraen, al menos, al año 4000 a. C.: para entonces ya se había preparado el lugar, como evidencia la presencia de una plataforma regular en la arcilla sobre la que se acumuló una gruesa capa orgánica, producto último de fuegos intensos acaecidos en el lugar. Esos carbones quedarían sellados con una primera tumulación de planta circular levantada en bloques irregulares de piedra cuarcítica. Los casi seis metros de diámetro y el metro aproximado (en su altura máxima) que tiene esta primera tumba nos remiten a un 
túmulo de dimensiones modestas en el contexto asturiano o cantábrico. Para colmo, la relevancia de esta estructura se vería seriamente mermada por el desarrollo sobre ella de otras dos arquitecturas prehistóricas que alteraron ese primer proyecto.

\subsection{SEGUNDA FASE}

El primer túmulo fue ocultado alrededor del 3800-3700 a. C. por una masa en forma de torus que destaca por la selección de los materiales empleados en su construcción, arcilla principalmente, además de por la originalidad en su forma. Ya desde la primera campaña de excavación se pudo identificar su sección semicircular (de entre dos metros veinte y dos metros treinta de anchura), conformada gracias a una amalgama de barros de texturas rojizas y anaranjadas que apenas mostraban inclusiones. Las arcillas seguían en todo momento trazados curvos que venían a enterrar la fase más antigua, definiendo una planta circular que dejaba un amplio hueco central. La segunda fase constructiva dio como resultado una estructura que superaba con holgura el proyecto inicial del túmulo pétreo, alcanzando casi los once metros de diámetro. En su zona superior se registraron evidencias inequívocas de combustión por lo que parece evidente la intención de que sobre el anillo ardieran fuegos, algunos con intensidad, igniciones que darían mayor relevancia al espacio. Las incandescencias sobre la arcilla facilitaron también la datación por termoluminiscencia de una fase constructiva muy parca, por otro lado, en materiales datantes (tanto relativos como absolutos) (R. del Cueto y Busto 2020: 60).

El hueco central del anillo fue colmatado parcialmente durante esta segunda fase, utilizando para ello una masa de tierra con barros y carbones que ayudaría a ocultar la masa del túmulo pétreo infrayacente. El relleno no era un material puro, como ocurría con la sección del torus, ya que en esa mixtura se amontonaron materiales de las dos fases constructivas que tenía hasta el momento ese espacio. Resulta complicado, si no imposible, determinar qué ocurrió en el punto central en cualquiera de estas dos etapas arquitectónicas iniciales. Cualquiera de los elementos, si es que hubo alguno, que se hubiesen erigido como parte de los monumentos quedaron sustituidos $\mathrm{u}$ ocultados (hasta hacerlos difícilmente rastreables) como consecuencia de la construcción del tercer proyecto. Uno en el que el nicho central resultó necesariamente socavado para que en él encontraran adecuada estabilidad todos los engranajes del nuevo elemento dolménico que se va a erigir a continuación.

\subsection{TERCERA FASE}

El tercer y último diseño megalítico de la Cobertoria supuso la construcción de una cámara de algo más de cinco metros cuadrados, a la que se accedía por un largo ingreso bien marcado por tres losas. En suma, un dolmen de corredor, modelo sin duda canónico dentro de los patrones del megalitismo europeo y que, en el ambiente arqueológico en el que nos encontramos, resulta de dimensiones bastante notables. La cámara ya denotaba la importancia del esfuerzo desarrollado, 
al tratarse de uno de los espacios de mayor amplitud, junto con el dolmen de Santa Cruz, de los que hasta el momento conocemos en la región (de Blas I983: 47). La riqueza arquitectónica del yacimiento quizá quedó inicialmente desmerecida en la bibliografía por su exhumación parcial, así como por la escasez de descripciones o de datos estratigráficos acerca de lo vaciado. La docena de ortostatos que, al menos, utilizaron para erigir el nicho funerario, y las dimensiones de algunas piedras, nos trasladan sin embargo a una escala de cierta relevancia en el contexto cantábrico. Es necesario mencionar que esa cámara dolménica central padeció diversas violaciones siempre en busca del tesoro legendario, dejándonos sin estratigrafías aprovechables para su estudio. Afortunadamente el acceso a la misma, descubierto en 2017, sí que atesoraba secuencias intactas convirtiendo a la Cobertoria de Salas en el único dolmen de corredor asturiano que presenta datos estratigráficos y dataciones absolutas sobre sus momentos de uso y abandono. El pasillo de entrada conserva sesenta centímetros de anchura, superando la abertura que se insinuaba en los dibujos y plantas previos de la cámara, y alcanzó el metro ochenta de longitud lo que lo convierte en el acceso de mayores dimensiones de los identificados en la región, al superar con holgura el del dolmen de la sierra de Pumarín (Bouza I965: I4-I5).

La construcción de la última fase supuso otras modificaciones del espacio construido. La masa tumular fue recrecida al menos en los dos extremos del eje principal, un incremento con el que el túmulo alcanzará los dieciocho metros de diámetro rozando los dos metros de altura en la cruz central. La dilatación del montículo no solo dio más coherencia y proporcionalidad al nuevo diseño ${ }^{9}$, sino que pudo favorecer un desplazamiento más llevadero de los monolitos de cuarcita que conforman el dolmen. Por último, una coraza de piedras de unos dos metros de anchura delimitó el borde externo del túmulo, y bien podría haber separado el terreno funerario del entorno, además de servirles para ocultar el costado exterior del torus arcilloso. Las dataciones radiocarbónicas analizadas aquí proporcionaron por fortuna datas bien aquilatadas, así como ajuares que permiten trasladar esta tercera fase a mediados del IV milenio antes de Cristo. Una fecha que podemos considerar dentro de la fase más madura del megalitismo regional (de Blas 2008: 525528), momento en el que además son frecuentes las ofrendas funerarias semejantes a las identificadas en la Cobertoria, tal y como ocurre con la lámina de cuarzo aquí recogida (R. del Cueto y Busto 2020: 65).

\subsection{REGISTROS ARQUEOLÓGICOS HISTÓRICOS DEL EXPOLIO DE LA RUINA PREHISTÓRICA}

Tras las ocupaciones prehistóricas el registro indica, por el momento, un largo periodo de abandono de la Cobertoria, que daría paso a una serie de alteraciones que podríamos vincular a actividades de expolio o saqueo. La ya mencionada codicia en

9. Gesto por otro lado muy acorde con lo que ya constatado en otros territorios megalíticos cercanos (Fábregas y Vilaseco 2004: 69). 
busca de tesoros motivó diversos accesos a la estructura prehistórica que supusieron modificaciones de las ruinas y de las secuencias originales y que, gracias al registro arqueológico, material y a las dataciones radiocarbónicas, hemos conseguido separar adecuadamente de las capas prehistóricas. También se han podido agrupar en una franja de tiempo de dos siglos: entre el XVIIl y el XX d. C. Las secuencias históricas de violación de la tumba prehistórica cuentan con una primera aportación en el VII Congreso Internacional del Neolítico en la península Ibérica, actas que serán publicadas próximamente y donde estas fases son descritas con cierto detalle.

\section{MATICES PREVIOS Y ALGUNOS PRECEDENTES EN EL MEGALITISMO TRIDIMENSIONAL Y LAS VISITAS VIRTUALES}

Los registros en tres dimensiones no son por supuesto una novedad, aunque su introducción en las excavaciones arqueológicas se está realizando de una forma paulatina o meramente puntual y no, desde luego, como práctica cotidiana. En el caso de la península Ibérica sí que habría que destacar algunos proyectos sobre megalitismo en el sur peninsular que han ejercido de pioneros muy destacados al generalizar el uso de técnicas fotogramétricas. Los conjuntos de Panoria y Menga, en diferentes áreas de Andalucía, son un buen ejemplo de la utilidad que tiene emplear drones, fotografías aéreas y nuevos programas (junto con la topografía con estación total), para así obtener series de información cada vez más precisas (Benavides et al. 2015; Caro y Hansen 2015; Benavides et al. 2016).

El megalitismo asturiano no cuenta con estructuras tan colosales en las que el corredor tenga decenas de metros de acceso cubierto hasta el interior de las cámaras. En el noroeste las arquitecturas son bastante más modestas y también por ese motivo ni los métodos a emplear, ni los resultados han de ser en ningún caso equiparables. La menor entidad tampoco debe ser un atenuante, pues el megalitismo supondría un esfuerzo igualmente importante para comunidades pequeñas y divididas como las que, muy seguramente, habitaron la región. Para la arqueología actual supone, además, un reto metodológico: aunque no hay duda que reduce el coste de aparatos y toma de datos, obliga a trabajar más el resultado final de cara a su presentación o para que ilustre un discurso histórico. Tampoco hay excesivas referencias de proyectos de excavación en el noroeste peninsular que hayan incorporado este sistema de documentación, y que luego hayan publicado de forma detallada su metodología y resultados. En este caso, la intención es inscribir el sistema de registro tridimensional en la toma de datos de una excavación en marcha, para así ponderar ventajas e inconvenientes generando un doble registro informativo. Por eso, los modelos tridimensionales se consideraron una parte más de la documentación, y no solo una filigrana para representar, puntualmente, zonas especialmente relevantes o propuestas de reconstrucción. También es necesario aclarar que la nueva tecnología en ningún caso vino a sustituir de forma inmediata el corpus clásico de información: dibujos, fotografía, topografía, etcétera. Al contrario, pues disponer de ambas fuentes permite cotejar la calidad y rapidez de la nueva documentación y compararla con los registros manuales. 
En cuanto a las visitas virtuales los ejemplos disponibles en red sobre proyectos arqueológicos vuelven a escasear en nuestra zona, aunque ya están en elaboración algunos recorridos aplicados a la difusión del patrimonio desde distintos enfoques y escalas de trabajo; puede ser el caso de las visitas a entornos urbanos y rurales o a yacimientos concretos. No hay duda que este recurso ofrece gran versatilidad al permitir acumular muchos y variados contenidos que pueden ir dirigidos a públicos específicos. La novedad que suponen ambos formatos en los proyectos de excavación y, especialmente, en las de periodos prehistóricos produjo que, en cierto modo, la metodología tuviera en nuestro caso un alto componente experimental. Desde luego que los ejemplos ya publicados en otras zonas son del mayor interés y se convirtieron en fuente de inspiración pero, en muchos casos, no todos los ejemplos que nos preceden encajan exactamente con los monumentos ni tampoco con las circunstancias y dificultades que rodean una excavación en el contexto de la arqueología cantábrica. Cada proyecto y equipo tienen también sus variables diferenciadas: principalmente el número de personas que forman el grupo, o los presupuestos con los que cuenta este. En nuestro caso ambas variables son, desde luego, muy modestas lo que no ha impedido un cierto desarrollo de este aspecto del que daremos cuenta, en cuanto al modo de trabajo, en el siguiente epígrafe.

\section{METODOLOGÍA DE REGISTRO Y DOCUMENTACIÓN}

Se describen a continuación los parámetros que hemos utilizado para realizar los modelos tridimensionales del dolmen de la Cobertoria así como los montajes para los recorridos virtuales a las necrópolis de San Juan y Penausén.

\subsection{REGISTRO FOTOGRÁFICO Y FOTOGRAMÉTRICO TERRESTRE (2016-2019)}

En nuestro caso, la fotogrametría terrestre fue desarrollada con el software de Agisoft Photoscan utilizando las fotografías tomadas con una cámara compacta digital (Agisoft PhotoScan Professional Versión I.2.4.; https://www.agisoft.com/; hoy denominado ya Agisoft Metashape). El programa, basado en la denominada structure from motion, computa información tridimensional a partir de una serie de imágenes fotográficas tomadas de manera estructurada. Una de las grandes ventajas de este programa es que solamente son necesarias unas pocas imágenes para hacer una buena reconstrucción. El resto de pasos a seguir o de peculiaridades del programa pueden ser consultadas en artículos muy generales sobre esta aplicación que sintetizan las ventajas del trabajo con este software (Verhoeven 20II; Doneus et al. 20II; De Reu et al. 20I3: IIIO-IIII).

Evidentemente, las fotos fueron tomadas en paralelo con las imágenes más convencionales, generando dos registros independientes que estaban salvaguardando el mismo proceso de excavación con fines totalmente distintos. Todas las fotografías tuvieron que adaptarse a las situaciones de cada campaña de trabajo y a sus ritmos. 
Por esta razón también desarrollamos protocolos de trabajo que permitieron que las tomas fuesen rápidas y de calidad, lo que sin duda hará más sencillos los posteriores trabajos para construir el modelo tridimensional.

Existen dos momentos clave durante las intervenciones arqueológicas: por un lado, el inicio de un área a excavar; por el otro, su finalización con la llegada a suelos donde ya no se identifica intervención humana (normalmente la roca o las arcillas basales). Son dos reportajes fijos que están presentes en todos nuestros sectores. Acompañando esas dos etapas, de arranque y cierre, se encuentran una serie de estadios intermedios del trabajo que también fueron fotografiados para realizar montajes tridimensionales. No hay un número pautado de estos pasos intermedios, ya que depende del interés o de la profundidad que tenga el sitio indagado. Nuestra propuesta siempre fue elegir un momento del avance de los trabajos que condensara información estratigráfica suficiente realizando, en casi la totalidad de los casos, una toma fotográfica al inicio y al final de la excavación de una unidad estratigráfica. Ello nos ha permitido poder reconstruir virtualmente el proceso de excavación y prácticamente todas las unidades estratigráficas han quedado documentadas con este sistema. Las áreas intervenidas debían ser retratadas además en condiciones de luz y limpieza suficientes, de una forma muy similar a lo que ocurre con los reportajes más clásicos de fotografía arqueológica. Cuando la luz no era ideal, por ejemplo, la excavación (y sus ritmos) siempre se amoldaron al registro. Esto podía implicar la detención momentánea de los avances en algún sector para ser tomado con una iluminación más adecuada; normalmente, a última hora de la tarde o primera de la mañana.

Si en el procesado de las imágenes para crear los modelos tridimensionales había cualquier elemento sobrante (personas, u otros elementos) que se quisieran eliminar de la fotogrametría, se creaba una máscara en Agisoft para eliminar su presencia, tal y como ya es clásico en el manejo del programa (De Reu et al. 20I3: IIIo). En vista de este hecho, y tras los primeros montajes, siempre se prefería que no hubiera elementos superfluos en la excavación para así evitar la creación de máscaras que siempre ralentizan el procesado del modelo. La descarga de las imágenes digitales con las que se construyeron los modelos se solía producir en tandas, creando «almacenes» independientes por carpetas para cada sector o sondeo. Gracias a ellos íbamos conociendo la calidad del trabajo para así repetir todo lo que no fuera de suficiente calidad. A partir de este acopio documental se podía iniciar la fase de creación en Agisoft de los modelos; en campaña esto solía ocurrir durante los días en los que la climatología no era adecuada para el trabajo de campo.

La tanda de fotos siempre trataba de cubrir completamente el área en excavación para así favorecer los solapamientos de datos y píxeles con los que trabajan los algoritmos. Como veremos, cada una de las zonas excavadas contó con una serie de hitos distribuidos por los bordes de la excavación que permitirían que el modelo, una vez alineado, también pudiera ser inscrito en la topografía con estación total que se estaba tomando cada año. Son los llamados «Puntos de control en el suelo» en traducción literal del término inglés y que son muy usados para georeferenciar desde hace tiempo (De Reu et al. 20I3: IIIo). Como ocurre con la fotografía tradicional las zonas más complicadas para las tomas son las sombreadas; en el caso de la 
Cobertoria este condicionante se notaba especialmente en la cámara funeraria, donde la altura de los monolitos generaba contrastes de luz muy fuertes entre zonas y por tanto lugares que el algoritmo reconstruye mucho peor en los modelos.

La densidad de instantáneas disponibles en las cámaras utilizadas en la excavación también produjo la necesidad de un sistema para identificar rápidamente, y separar, los reportajes (el clásico y el tridimensional). Todo ello mediante una pizarra que incluía información básica (campaña, fecha, sector y unidades afectadas), de tal modo que luego la descarga y el procesado del archivo gráfico resultara más sencillo. Debido a que la excavación, las zonas a intervenir y también la profundidad de estas fue aumentando progresivamente, se hizo necesario que el registro fotogramétrico creciera también a la par. Así, mientras que en el año 2016 se crearon 23 modelos de unidades estratigráficas y del proceso de excavación (más uno inicial anterior a nuestra intervención), durante 2018 ya acumulamos medio centenar de modelos esa campaña subiendo, en 2019, el número hasta 58. Toda esta información nos permite reconstruir el proceso de excavación, realizar revisiones y nuevas lecturas, tanto por parte de los miembros actuales del equipo como, en un futuro, por el resto de la comunidad científica. Al mismo tiempo nos permite seguir extrayendo información, como el cálculo de áreas o la reconstrucción de volúmenes; todos ellos datos esenciales sobre realidades arqueológicas que ya no existen materialmente.

\subsection{REGISTRO FOTOGRÁFICO $Y$ FOTOGRAMÉTRICO AÉREO (2016 Y 2019)}

Las técnicas de fotografía aérea con drones ya no pueden representar una sorpresa o una novedad en sus aplicaciones a la arqueología. Por ese motivo aquí no abordaremos las especificidades de los sistemas con los que trabajan ni tampoco sus aplicaciones, pues hay un largo recorrido bibliográfico al respecto (Verhoeven 20II). Pasaremos, más bien, a relatar nuestra experiencia en el uso de estos ingenios, pues sobre el megalito se realizaron dos vuelos de dron en diferentes años: 2016 y 2019. Los modelos de drones utilizados fueron un DJI Phantom 3 Advanced y un Phantom 4 PRO, con resoluciones de las cámaras de 12.4 y $20 \mathrm{Mp}$, respectivamente. Las focales equivalentes de las cámaras son de $20 \mathrm{~mm}$ y $24 \mathrm{~mm}$ (35mm equiv).

Los vuelos realizados fueron diversos: los hubo con cámara vertical a varias decenas de metros para cubrir el emplazamiento al completo y relacionarlo con el entorno cercano, y en los que se emplearon herramientas de vuelo autónomo para garantizar el recubrimiento adecuado de las imágenes. Para los modelos de detalle se realizaron vuelos manuales con disparo por tiempo fijo (de 2s en general) o manual, cuidando la geometría de las capturas y adaptándolas a las posibles ocultaciones y configuración de los ortostatos y otros elementos. Todas las imágenes son geoetiquetadas por el sistema GNSS (Global Navigation Satellite system) con las coordenadas de navegación del dron. Se realizó también un vuelo experimental con otro dron distinto de los anteriores dotado de una cámara multiespectral, Parrot Sequoia con canales NIR, Red Edge además de los canales visibles. El objetivo era procurar deducir, de forma indirecta, la posible existencia de otros elementos rocosos enterrados en los bordes 
aún no excavados en el entorno del dolmen a partir de un reflejo indirecto sobre la vegetación superpuesta. Desgraciadamente, no se obtuvieron resultados ante la falta de vegetación homogénea en los bordes de la excavación, el estado ya removido de la capa superficial del entorno de la misma, y la ausencia de rocas en el subsuelo cercano. Durante el año 2016 el primer vuelo generó i7i fotografías que retrataron una fase muy inicial de la excavación (Figura 6), mientras que el segundo, realizado en 20I9, captó 337 (Figura 7). Como vemos, este segundo vuelo tomó un mayor número de imágenes, a pesar de que las condiciones de viento no eran muy adecuadas, lo que impidió elevar el dron a las mismas alturas que en 2016.
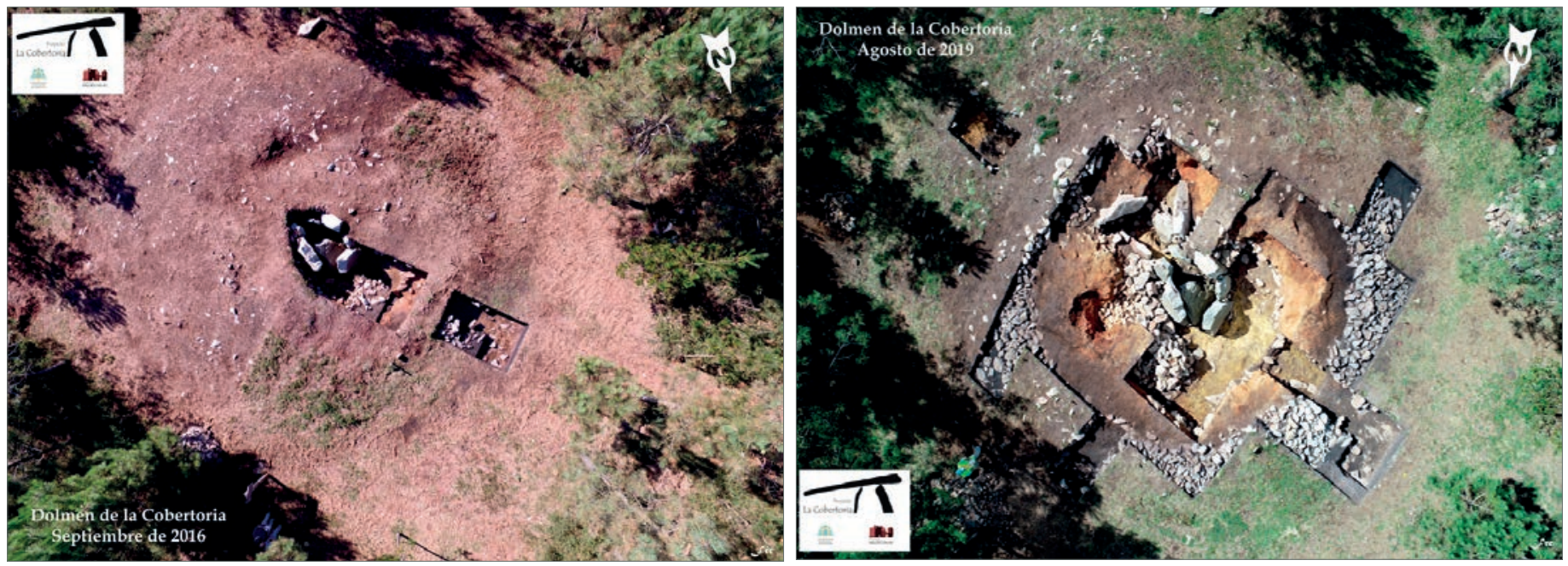

FIGURA 6. IMAGEN DEL TÚMULO DURANTE EL VUELO REALIZADO SOBRE EL FIGURA 7. IMAGEN DEL TÚMULO DURANTE EL VUELO REALIZADO SOBRE EL YACIMIENTO EN 2016 YACIMIENTO EN 2019

Tales registros supusieron sin ninguna duda un suplemento informativo notable con el que mejorar la comprensión del monumento, aparte de que proporcionó imágenes de gran calidad que son esenciales para la elaboración de presentaciones o de figuras que luego iban a ser publicadas en artículos científicos. Desgraciadamente, solo pudimos incorporar el dron a momentos puntuales y en ningún caso formó parte del día a día de la excavación. A pesar de la novedad que supone el uso de drones en el megalitismo asturiano tampoco era nuestra pretensión, de momento, realizar a partir de los vuelos microtopografías detalladas del túmulo, como las ya realizadas en otros ámbitos donde se enfrentan a arquitecturas de mayor monumentalidad y complejidad (Benavides et al. 2015: 206-207).

Aparte de los 3D de cada sector parcial de la excavación también ensamblamos, a partir de los vuelos del dron y sus imágenes, dos modelos tridimensionales de la masa tumular completa; ambos ya están disponibles en el perfil de sketchfab que tiene el proyecto de la Cobertoria (Figura 8). Sin duda son aproximaciones iniciales sobre los que habrá que seguir trabajando, pues los formatos digitales son muy completos y permiten muchas mejoras. Tanto los recursos web enumerados como este texto, que resume nuestras propuestas y metodología, son de los pocos ejemplos disponibles de tales recursos para este campo del megalitismo en el noroeste peninsular, una vía que seguramente será muy utilizada en los próximos años pero que de momento ha sido 
poco explorada. Hablamos, desde luego, de utilización por parte de investigadores y de proyectos científicos, pues el cotejo de modelos existentes en sketchfab sí que depara múltiples creaciones por parte de empresas del sector que están ofertando estos servicios, o de aproximaciones arqueológicas no profesionales.

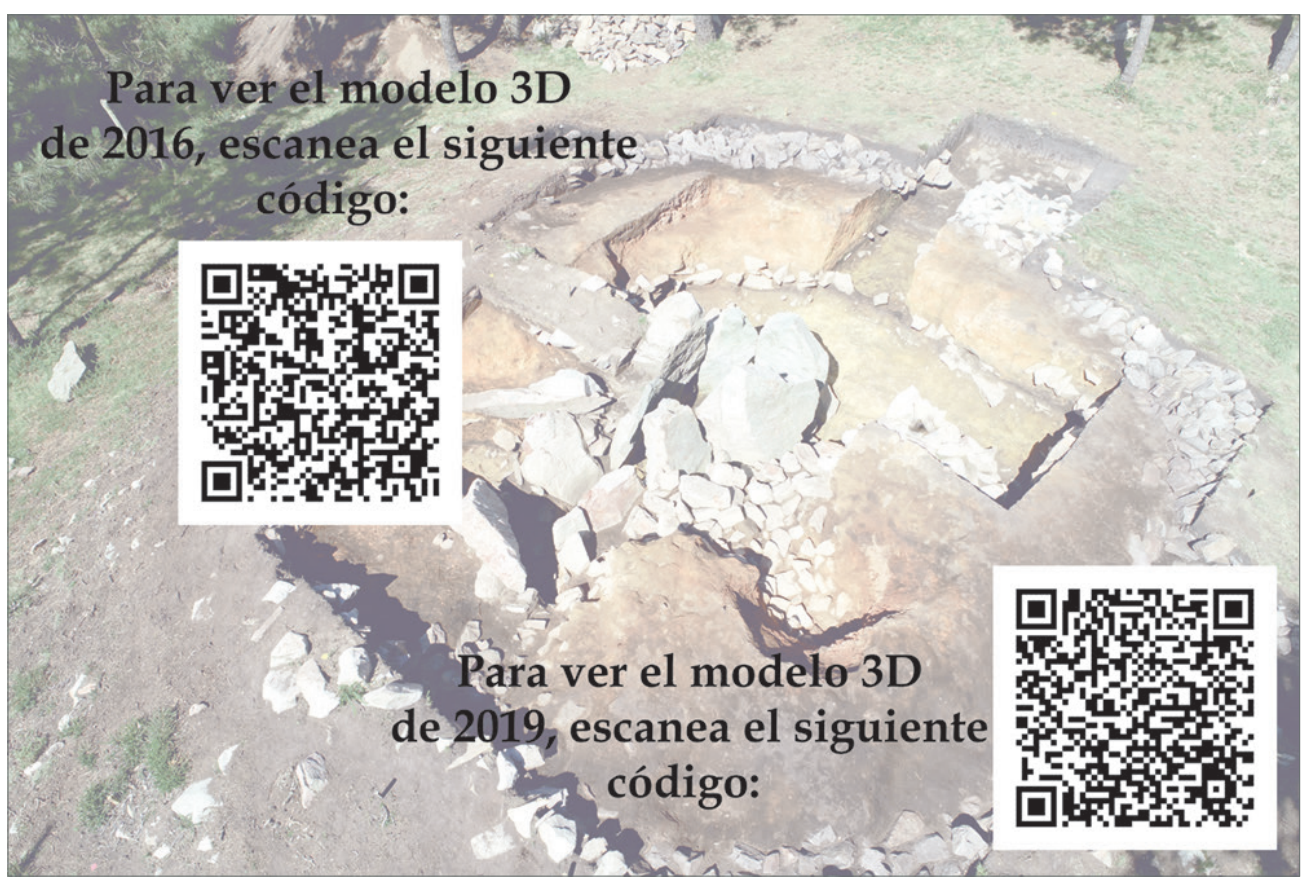

FIGURA 8. CÓdIGOS QR PARA ACCEDER DESDE ESTE ARTÍCULO A LOS DOS MODELOS 3D YA DISPONIBLES EN SKETCHFAB

\subsection{TOPOGRAFÍAS Y GEOREFERENCIACIÓN}

La puesta en marcha de un registro topográfico que permitiera la georreferenciación de toda la información generada durante el proceso de excavación ha sido fundamental desde los inicios del proyecto. A la conclusión de las campañas de 20I6, 20I7, 2018 y 20I9 se realizaron barridos topográficos por las zonas intervenidas cada año. Para arrancar con la topografía con estación total se fijaron y georreferenciaron dos bases de referencia o «puntos cero» que serían luego fundamentales para el resto de los trabajos de registro y documentación. A partir de estos puntos se levantaron anualmente: un plano taquimétrico que cubre todo el entorno del monumento; otro que topografía la estructura tumular y un último plano que recoge con gran detalle el final de cada una de las campañas georreferenciando todos los sondeos, sus perfiles y las unidades estratigráficas expuestas. Las topografías realizadas con estación total nos han permitido aunar toda la información generada en nuestros registros fotogramétricos aéreos y terrestres. Gracias a ella todo está georreferenciado y podemos obtener modelos digitales del terreno de gran precisión seleccionando, en cada momento, las técnicas que nos resulten más oportunas (Figura 9). Conforme el número de modelos 3D fue aumentando los «Puntos de control en el suelo», que cada año eran georreferenciados durante el proceso de topografía, ganaron también 
más peso. Gracias a este compendio de registros podemos dotar de coordenadas a todas las unidades estratigráficas y al registro material hallado en la excavación.
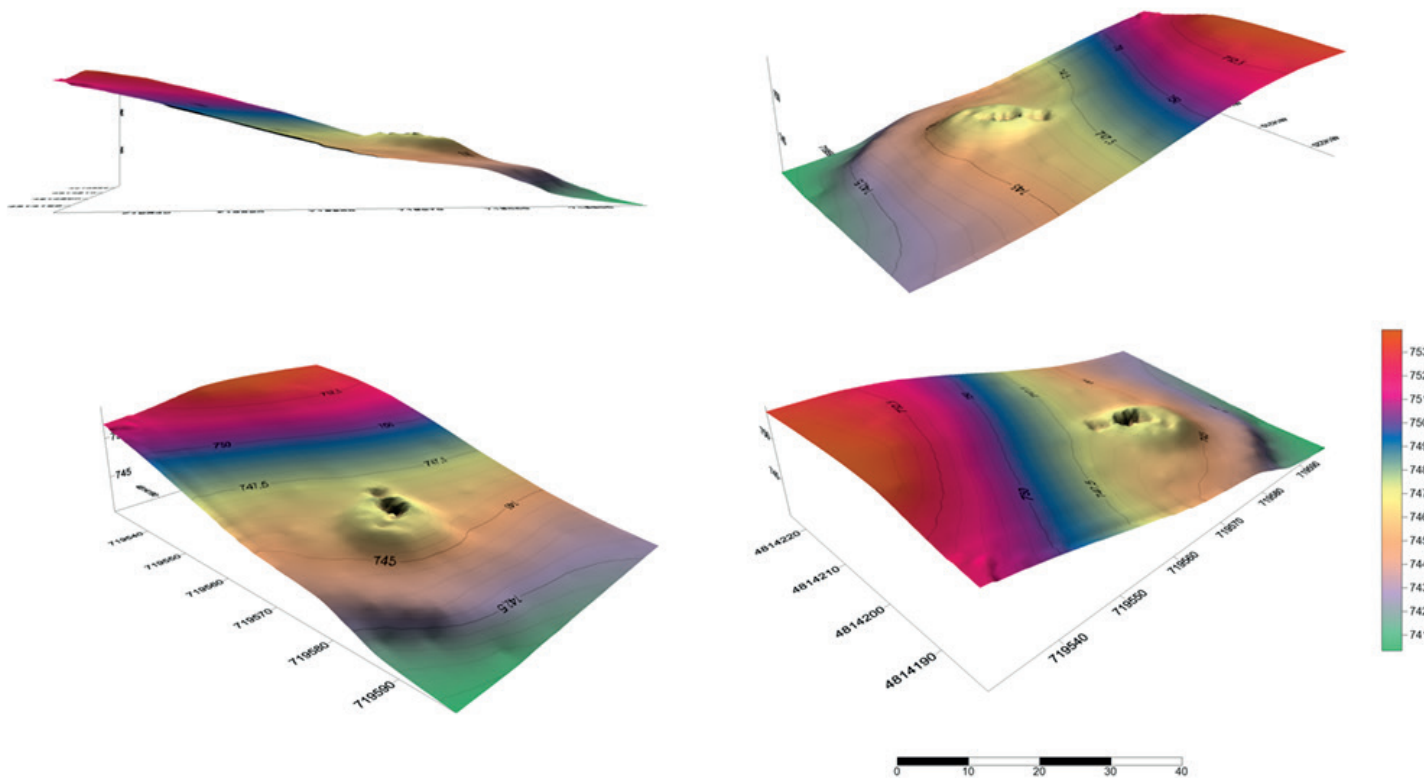

FIGURA 9. MONTAJE REALIZADO A PARTIR DE 4 MODELOS DIGITALES DEL TERRENO OBTENIDOS A TRAVÉS DE LA UNIÓN DE LOS DATOS TOPOGRÁFICOS Y DEL MODELO FOTOGRAMÉTRICO AÉREO REALIZADO EN 2OI6. Imagen de Miguel Busto

\subsection{VISITAS VIRTUALES (2019)}

El objetivo principal era disponer de recorridos virtuales de los conjuntos tumulares de San Juan y de Penausén, visitas que pudiésemos incluir en la web y, al mismo tiempo, nos sirvieran para talleres específicos con un fuerte peso en formatos digitales. La demanda volvía a generar la necesidad de disponer de estos recursos, pues tanto el Instituto de Enseñanza Secundaria Arzobispo Valdés-Salas, como el Colegio Público Chamberí, ambos de Salas, junto con el taller de infancia vinculado al Ayuntamiento de esta localidad, nos habían solicitado actividades con las que acercar nuestros trabajos a la comunidad educativa. Los materiales en $3 \mathrm{D}$, por su atractivo para todo tipo de público así como por su carga de novedad, resultaban un estímulo ideal para trabajar en la divulgación del patrimonio (Figura Io).

Por fortuna, el Observatorio del territorio del departamento de Geografía de la Universidad de Oviedo inició una línea de investigación sobre la Realidad Aumentada (RA) y la Realidad Virtual (RV) con aplicaciones en la docencia y el turismo. Como resultado, varios talleres y charlas en centros educativos utilizaron recorridos virtuales con el fin de explicar los paisajes patrimoniales y culturales. Así, hoy disponemos de varios itinerarios didácticos en la web del observatorio ${ }^{\mathrm{IO}}$ : «Gijón aumentado», «Oviedo aumentado», «Itinerarios didácticos por Luarca»,

10. http://www.observatoriodelterritorio.es/ 


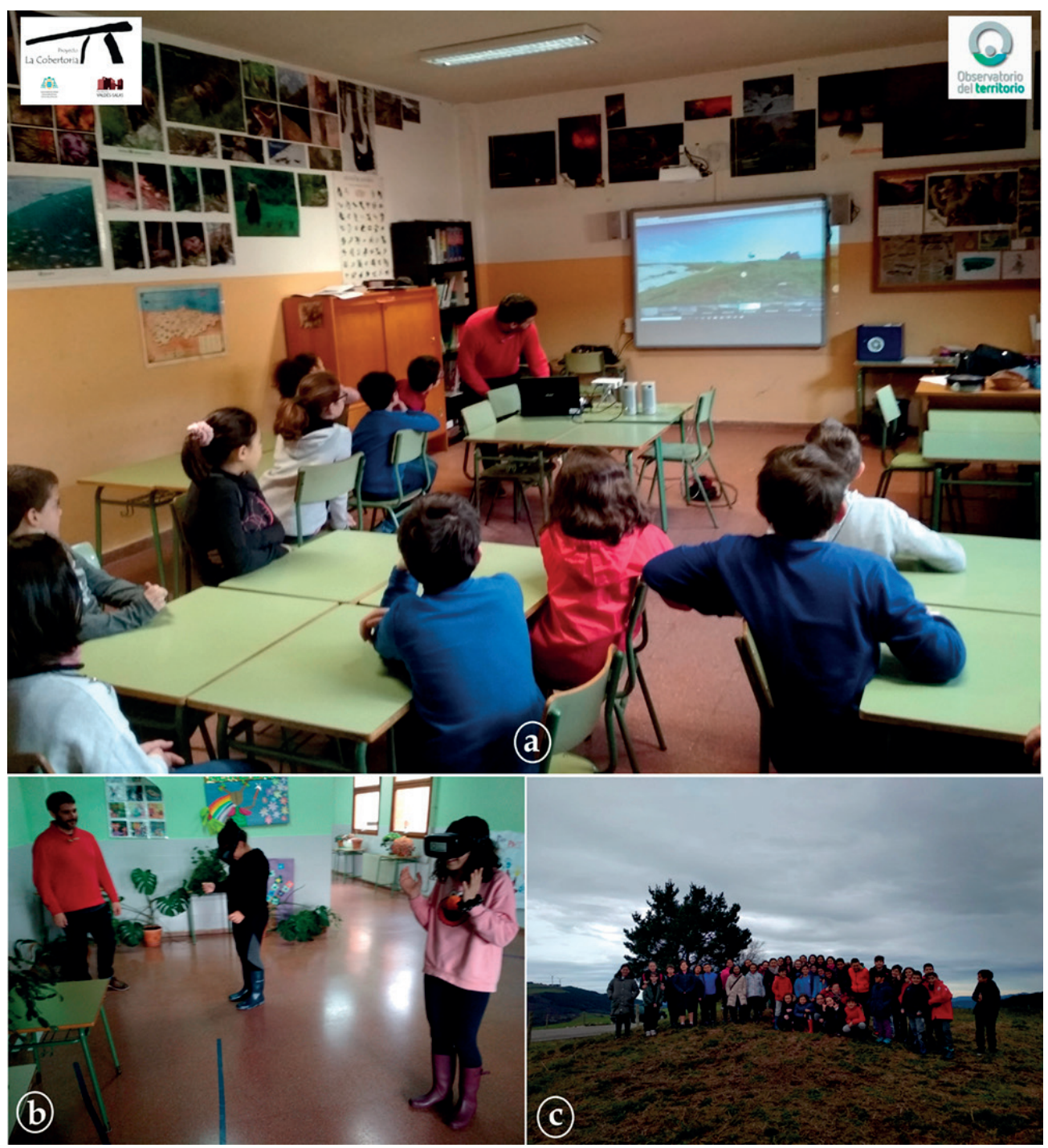

FIGURA 10. IMÁGENES DEL TALLER DE MEGALITISMO 3D EN EL COLEGIO PÚBLICO CHAMBERÍ DE SALAS: A) VISIONADO DE LAS VISITAS VIRTUALES; B) RECORRIDO CON GAFAS 3D POR LAS VISITAS; C) VISITA A LA NECRÓPOLIS DE PENAUSÉN

«Itinerario por las hoces del Esva», entre otros. Todos ellos de utilidad como materiales didácticos en diversos grados educativos, ya que permiten establecer una mayor interacción con el alumnado y favorecen que este identifique elementos significativos en cada recorrido. En el caso que nos ocupa, la elaboración de estos materiales ha supuesto la colaboración interdisciplinar entre prehistoriadores y geógrafos, algo sin duda enriquecedor y beneficioso para ambas partes. Con ellos se ha intentado combinar el conocimiento de primera mano de los yacimientos con la integración de los mismos en el paisaje circundante.

Para ello se realizaron dos tandas de fotografías a ambas necrópolis: una en la primavera de 2019 que permitió un montaje preliminar y que pudiésemos satisfacer los primeros encargos de talleres que nos habían realizado. Con ese primer acercamiento se fijaron también los puntos de interés en cada uno de los recorridos. 
En el verano de ese mismo año se pudieron repetir ambos barridos con fotos de mayor calidad. Dos factores resultaron fundamentales para que hubiera mejores instantáneas en este segundo intento: en la necrópolis de Penausén, durante la primera visita, todavía no se había realizado la limpieza anual que tiene programada este lugar. En períodos estivales la excavación de la Cobertoria presenta también mejor aspecto, al estar totalmente descubierta (durante el invierno se oculta para protegerla de la climatología), y en buen estado de limpieza. Para la toma de las fotografías se utilizó una cámara 360 grados, modelo Samsung Gear 360 que, aunque no es una cámara profesional, cumple ampliamente los requerimientos de este tipo de proyectos a un bajo coste. Las fotos pueden ser visualizadas en el PC, en dispositivos móviles y de una forma más inmersiva mediante los conocidos como Head Mounted Display (HDM) como las gafas para realidad virtual (Figura Iob).

Los recorridos se realizaron mediante fotografías $360^{\circ}$ esféricas que posteriormente fueron editadas para eliminar imperfecciones. Las imágenes esféricas permiten una visión completa de los yacimientos y su entorno inmediato. Mediante la plataforma web Roundme también es posible enlazar las diversas fotografías de cada yacimiento estableciendo así un itinerario por el que «moverse» de una manera sencilla. En estos fotogramas se han incluido «hotspots» con información adicional en el que se explican las principales características de cada lugar y en los que, además, es posible incluir contenidos multimedia que ayuden a su interpretación. Uno de ellos fue utilizado aquí para mejorar y facilitar la guía: los audios explicativos. Por último, siempre se escogieron puntos clave que permiten una visión privilegiada de las necrópolis. Con todo ello montamos dos itinerarios con distintos protagonistas pero que se podían complementar bien (Figura II). En el primero, el de San Juan, se visitan las estructuras funerarias en su situación actual, con todas sus características morfológicas, así como su ubicación en el entorno. Dentro de esta visita está el dolmen de la Cobertoria que nos ofrece una visión de una excavación arqueológica en funcionamiento con la que, por tanto, comprender in situ la estructura interna de uno de los túmulos y sus distintos registros arqueológicos. Una vez generados los recorridos se incrustaron en la página web del proyecto para que estuvieran fácilmente accesibles al público. En la segunda visita, la de Penausén, disponemos de un paseo más general por un conjunto formado por varias tumbas prehistóricas, todas ellas próximas entre sí reforzando la idea de agrupación y por tanto de cementerio de estas comunidades.

Las visitas se desarrollaron a partir de una serie de puntos clave dentro de la necrópolis que, o bien son interesantes en lo visual, o bien lo son desde lo arqueológico; algunos combinaban ambos aspectos. Es normal que mezclásemos los dos enfoques pues en la visita se incluyeron tanto apreciaciones específicas (sobre lo que está en primer plano de la imagen), como matices más generales sobre este tipo de cementerios; también sobre el entorno cercano a las necrópolis y su integración en el paisaje histórico actual. No olvidemos que la intención principal era explicar estos conjuntos, sus tumbas principales así como la forma de vida neolítica que las propicia; todo ello con un discurso divulgativo que evitara caer en efectismos visuales. Más bien se perseguía dotar a la visita guiada de información de calidad desde el punto de vista científico (Orlandi et al. 20I4). Las explicaciones 
siempre tuvieron un carácter general y didáctico, utilizando para enhebrar el discurso grabaciones de audio que se inician cuando se accede a cada punto de la visita. Junto a los audios, también se añadieron al recorrido virtual imágenes y textos desarrollados por el proyecto que, por otro lado, ya formaban parte de las explicaciones volcadas a la web sobre ambos lugares.

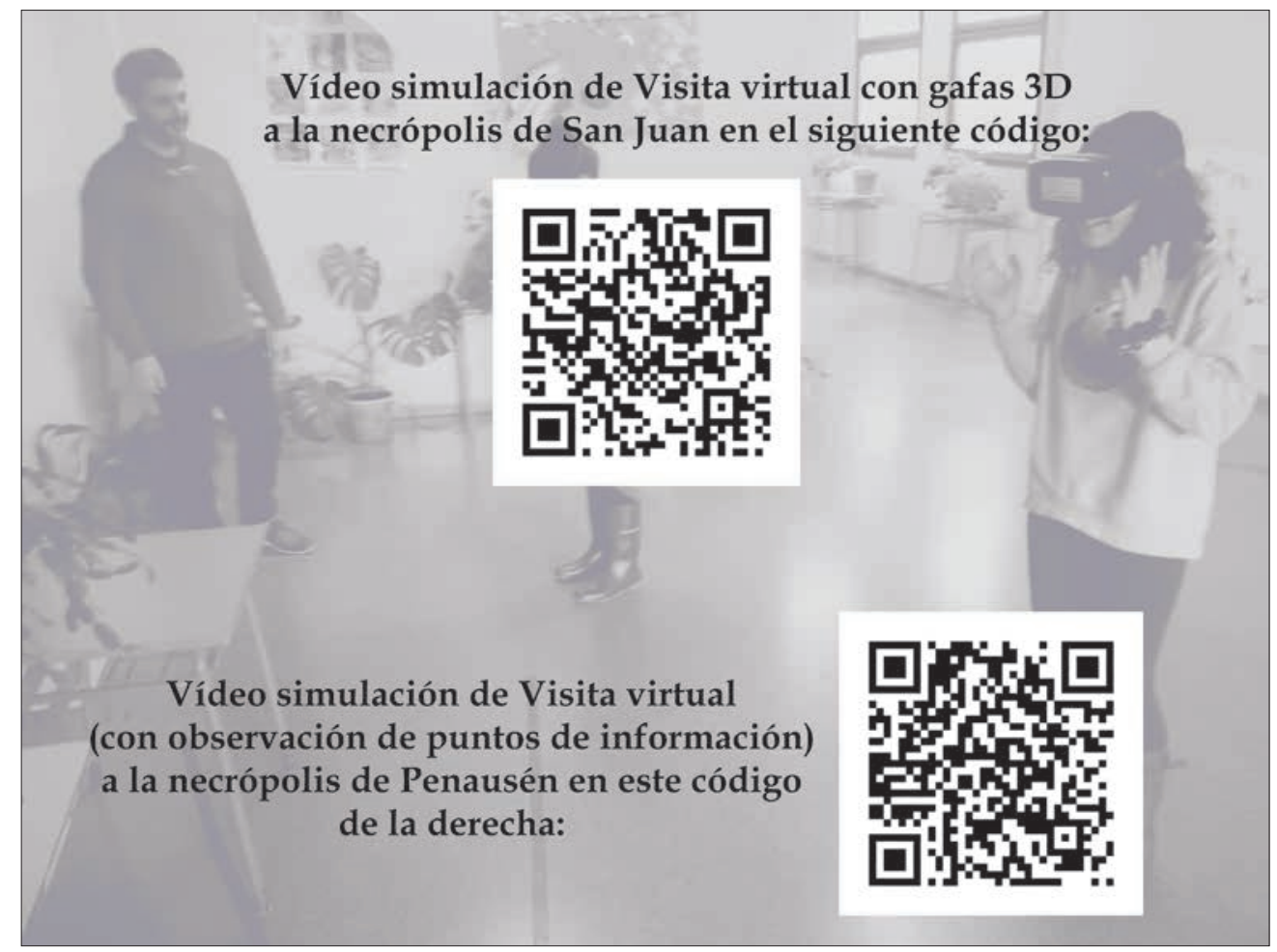

FIGURA 11. CÓDIGOS QR CON DOS VÍDEOS SOBRE LAS DOS VISITAS VIRTUALES SUBIDAS. EL DE LA PARTE SUPERIOR, ESTÁ PREPARADO PARA VISUALIZACIÓN CON GAFAS DE REALIDAD VIRTUAL.

\section{POSIBILIDADES DE LAS NUEVAS HERRAMIENTAS EN LOS PROYECTOS DE INVESTIGACIÓN}

\subsection{DIVULGACIÓN Y RECURSOS WEB}

Casi resulta redundante resaltar las bonanzas y posibilidades de los modelos tridimensionales: su facilidad de manejo, eficacia y bajo coste amparan su constante y creciente uso. En Arqueología facilita mucho poder concentrar los datos de un entorno excavado en un único medio, dado que los $3 \mathrm{D}$ incluyen superficies horizontales (plantas, suelos, hoyos y unidades negativas, etc.), junto con elementos verticales (como perfiles y secciones arqueológicas o estructuras). Así, no es extraño que estemos ante una herramienta de la mayor utilidad al ser completa y de uso sencillo. Si uno quiere acceso rápido a toda esa información no tiene ni siquiera 
que abrir el programa: bastaría con exportar el archivo a PDF, un formato que carga rápido y que no pierde excesiva calidad (Verhoeven 20II: 72).

El modelo, además, es únicamente el punto de partida que da muchas posibilidades de edición posterior: por ejemplo, para la creación de figuras que luego se van a incluir en publicaciones científicas; añadiendo los datos estratigráficos o documentales necesarios el $3 \mathrm{D}$ nos puede resultar muy útil. Ya lo es como creación al compendiar en un solo archivo múltiples enfoques y posiciones de la cámara de la misma realidad; un acercamiento que siempre es más complicado de conseguir con un reportaje fotográfico convencional. Además, las visiones diferenciadas nos acercan más a la evidencia arqueológica, ya que un perfil, un suelo o un hoyo, siempre se pueden ver desde diferentes ángulos o puntos de vista.

En el proyecto de la Cobertoria se han desarrollado medidas de registro tridimensional que aún son básicas, pero no por ello menos interesantes o novedosas en nuestro contexto de trabajo. Tampoco son difíciles de incorporar en el día a día de una excavación, aunque todavía haya escépticos o reticentes al uso de estas herramientas: mucho menos cuando aquellos que tienen proyectos con suficientes medios ya están proponiendo la utilización de técnicas como el $3 \mathrm{D}$ desde el mismísimo «borde del paletín» (Berggren et al. 2015; Dell' Unto et al.: 635-636), utilizando la traducción de esta elocuente expresión inglesa. Aunando el 3D de la excavación junto con una georreferenciación en SIG de alta calidad de los hallazgos se podrían construir los modelos tridimensionales «en directo», en el propio campo, y de forma síncrona con la propia excavación. Un sistema que se ha empezado ya a aplicar a yacimientos prehistóricos mesolíticos nórdicos y que, desde luego, es una forma de registro altamente precisa (Dell' Unto et al. 2017: 635-636). Al no haber demora en el procesado de los modelos 3D evitamos el callejón sin salida de que lo excavado ya haya desaparecido. Debemos recordar que el procesado de los modelos siempre se suele realizar en fases posteriores de laboratorio, una vez finalizada la excavación. Cuando esto ocurre, los errores en la estrategia o en el registro ya no se pueden subsanar. Sin embargo, sí se podrían corregir cuando excavación y registro tridimensional se están compatibilizando y ejecutando al unísono. Entre las grandes mejoras que incorpora este sistema de documentación siempre se mencionan las siguientes: tener la posibilidad de revisar pasos previos dados en excavación; tener referenciado el registro material en tres dimensiones, estableciendo así conexiones espaciales entre hallazgos, por ejemplo, de diferentes años; $y$, por último, las facilidades con la que se puede construir una matriz de la excavación o reconstruir mediante volúmenes sólidos las unidades ya excavadas (Dell' Unto et al. 2017: 642-643). La única parte negativa es que añadir estas herramientas es siempre muy costoso y, de momento, no podrá ser asumido por todos los equipos de excavación.

Una consecuencia del uso de estas aplicaciones es que los museos digitales, sobre yacimientos o sobre materiales arqueológicos, cada vez serán más cruciales, al ejercer de repositorio web de la información procesada. Así, los proyectos que ya están potenciando este aspecto son referencia clave para nosotros: desde la necrópolis etrusca de Tarquinia a Çatalhöyük, pasando por casos ibéricos (Remondino y Rizzi 2010: 94; Berggren et al. 2015; Díaz et al. 2015). Destacar sobremanera aquellos casos 
donde la aplicación está vinculada al megalitismo y, en algunos casos, al megalitismo norteño (López-Romero 2014; López-Romero et al. 20I5; López-Romero et al. 20I5b; López-Romero et al. 2016). La reproducción de modelos o de rutas virtuales mediante gafas 3D no es la única salida: la impresión digital de maquetas de estructuras, zonas en excavación o de materiales es ya una realidad con muchísimas posibilidades a corto, medio y largo plazo. Hoy en día, y especialmente en un proyecto de referencia para el campo del 3D como Çatalhöyük, ya se llega incluso un paso más allá de la reconstrucción 3D. Sus publicaciones incentivan la reflexión sobre los discursos que se están creando en las historias de las casas de este asentamiento. Con ello la reconstrucción no es solo una virguería técnica o documental: más bien persigue que esté dirigida a todo tipo de públicos y que atienda correctamente las representaciones de clases, razas, etnicidades o género (Lercari 20I7).

En cuanto a las visitas virtuales son un recurso fundamental, pues permiten, en cualquier circunstancia y lugar, un acceso guiado muy completo a los yacimientos. Además, se pueden ofrecer visualizaciones completas que sobrepasan las vistas parciales de las fotografías convencionales (Orlandi et al. 20I4). Otras ventajas que supone la elaboración de visitas virtuales podrían ser las siguientes:

* Nos dan la posibilidad de conocer las características fundamentales de cada una de las ubicaciones estudiadas, que pueden ir acompañadas de materiales multimedia e incluso tridimensionales que facilitan su lectura e interpretación.

* Como recurso didáctico complementario de la vista presencial, donde también tiene indudables posibilidades didácticas. Tanto como material previo y preparatorio de la propia visita, como a modo de recurso con el que reforzar o ahondar en ciertos detalles de los sitios arqueológicos.

* Su carácter inmersivo permite realizar un recorrido incluyendo partes del yacimiento no visitables, debido a su fragilidad o a su estado de conservación.

* Constituyen un medio de acercamiento a aquellos lugares arqueológicos que no puedan eliminar sus barreras arquitectónicas. Con estas visitas se estaría garantizando la participación de personas con movilidad reducida.

* A su vez permiten la difusión de aquellos sitios en los que la accesibilidad puede resultar peligrosa para el público.

Algunas de las oportunidades que ofrecen las visitas virtuales quedaron plenamente de manifiesto durante el confinamiento de 2020, producido por la pandemia del coronavirus. Esta reciente reclusión ha reafirmado la importancia de esas entradas web remotas, pues ha dotado a los proyectos que ya disponen de ello de una plataforma digital muy cómoda para dar a conocer el patrimonio. En nuestro caso ya tenemos el primer paso dado y sería deseable que en un futuro se puedan articular visitas más completas añadiendo otras herramientas adicionales que han demostrado su utilidad dentro de recorridos megalíticos virtuales, caso de los game engines ya aplicados al caso de Menga (Caro y Hansen 2015).

Además, las herramientas digitales están proporcionando nuevas formas de documentar los yacimientos complementarias de las tradicionales y que se desarrollan sobre nuevos soportes que sobrepasan la bidimensionalidad de los informes y 
artículos tradicionales. De este modo, la Realidad Aumentada (RA), entendida como el resultado de superponer al mundo real elementos virtuales (Azuma 1997: 356), supone una oportunidad de incluir nuevas formas de representación e información, imprescindibles en la actualidad para un acercamiento más profundo, real y cercano a las excavaciones arqueológicas. La aplicación de la RA a la musealización ha sido ampliamente tratada por diversos autores (Escaples et al. 2013); sin embargo, permanecieron menos estudiadas las posibilidades que ofrece en el ámbito de la transmisión del conocimiento. Especialmente, en el contexto actual en el que los materiales digitales tridimensionales e interactivos constituyen una parte fundamental dentro de las propias excavaciones, pues la realidad aumentada permitiría reunir esos materiales posibilitando la adaptación de los contenidos a los destinatarios finales. Para ello, es necesario contar con hipervínculos o marcadores que permitan «aumentar» la información mediante elementos digitales, fácilmente integrables en los nuevos formatos (Craig 20I3). Por nuestra parte se han añadido, muy recientemente, aproximaciones virtuales a las sierras donde están emplazadas las dos necrópolis que tienen también visitas online; unos acercamientos que ya están disponibles también en red. Estos visionados más globales de la montaña, realizados a partir de Google Earth, permiten apreciar la morfología en 3D del espacio natural donde fueron construidos los túmulos prehistóricos, que aparecen perfectamente localizados al utilizarse los datos GPS recabados en las prospecciones. En suma, un itinerario más paisajístico de los cementerios prehistóricos, que sirve de perfecto complemento a la visión sobre el terreno (más detallada, pero de menos alcance territorial) que nos proporcionan las visitas virtuales. El desarrollo de un discurso en audio sobre cada conjunto, combinado con imágenes, y las planimetrías de cada uno de los lugares, permitió montar dos vídeos muy dinámicos actualmente disponibles en abierto en Youtube y que fueron promocionados en las distintas redes sociales del proyecto.

\subsection{EL MUNDO TRIDIMENSIONAL COMO PARTE DE LOS REGISTROS DE EXCAVACIÓN: LUCES Y SOMBRAS}

Hasta aquí se han glosado suficientes características positivas del uso de lo tridimensional en el registro arqueológico. No hay que olvidar una característica aún no resaltada: la rapidez y eficacia con la que, a partir del mundo 3D, se pueden crear registros más clásicos de información arqueológica. Con esa intención en 2016 levantamos una sección completa uniendo los dos principales perfiles de la excavación; todo ello a partir de un modelo creado con Agisoft a partir de precedentes ya publicados (Benavides et al. 20I6). En ambas secciones teníamos las que, en ese momento, eran las unidades estratigráficas «clave» para entender los acontecimientos constructivos esenciales del túmulo. La sección «digital», fue cotejada con otra que, representando mismos acontecimientos y protagonistas, habíamos tomado mediante métodos más tradicionales (papel milimetrado y mediciones con teodolito). Nos parecía una forma provechosa de comparar herramientas y decidir si resultaba rentable continuar con la apuesta por el doble 


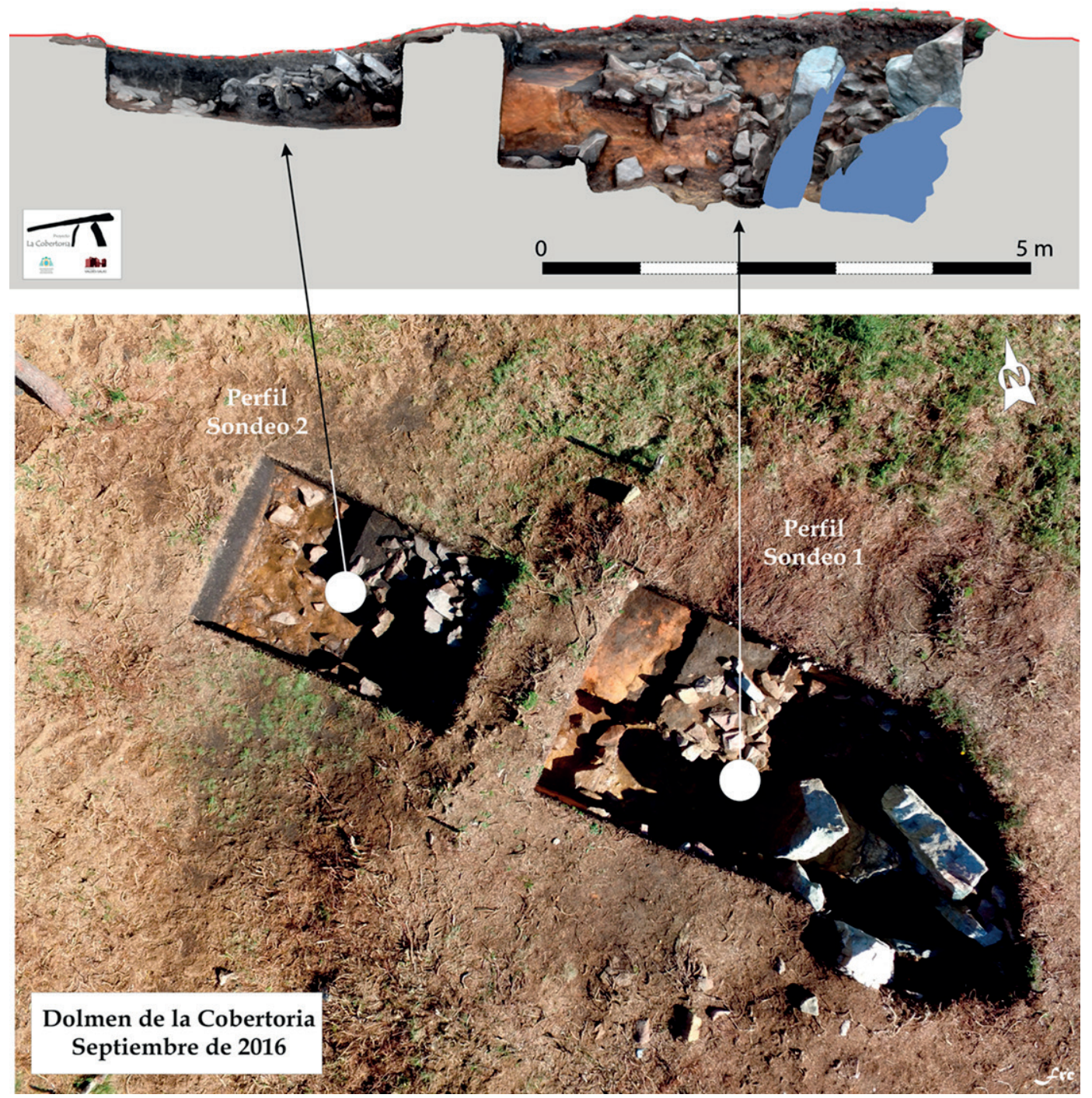

FIGURA 12. INFERIOR: IMAGEN DE LA EXCAVACIÓN EN 2016 DESDE EL DRON, CON INDICACIÓN DEL PERFIL DE LA EXCAVACIÓN DIBUJADO. SUPERIOR: PERFIL CONSTRUIDO A PARTIR DEL MODELO TRIDIMENSIONAL

registro: fotográfico clásico y fotogramétrico terrestre. En el fondo también éramos conscientes de que esa dupla informativa iba a absorbernos mucho tiempo y esfuerzo, y de que las herramientas nuevas siempre hay que someterlas a distintos test de fiabilidad. La superposición de ambos registros indica la corrección del perfil digital que, evidentemente, requiere de menos tiempo en campo para la toma de datos, pero que siempre demanda más esfuerzos de edición en laboratorio: tanto para el montaje del modelo, como para luego aislar en este la sección (Figura 12). La forma que nos traslada el tridimensional es otro factor añadido que siempre es remarcado en las publicaciones como una gran ventaja de este sistema (Benavides et al. 2016: 504; De Reu et al. 2013: III8).

Por último, no queremos tampoco ignorar ni soslayar algunos problemas generados por los algoritmos con los que trabaja Agisoft. Mucho de ellos vienen 
derivados del protocolo utilizado para tomar los datos, o del utilizado a posteriori para procesarlos. En primer lugar, y dado que siempre se suele trabajar con modelos decimados o mermados, esto puede afectar a la calidad del tridimensional final (Remondino y Rizzi 2010: 93; Benavides et al. 2016: 498). También puede ocurrir que, si no aportamos suficiente información al programa, este tendrá que rellenar las zonas extrapolando los datos de los píxeles de su entorno, produciendo así cierto «falseo» de la nueva imagen 3D. Por último, si utilizamos diferentes sensores a diferente resolución geométrica algunas características podrían cambiar ligeramente después del «centrifugado» de las fotografías que ejecuta Agisoft, afectando a la calidad del resultado (Remondino y Rizzi 2010: 93-94). Las dificultades son por tanto bien conocidas desde los primeros usos arqueológicos de la aplicación, lo cual ha permitido tenerlas en cuenta e ir trabajando progresivamente en su resolución.

Además, y siempre y cuando estas nuevas herramientas sean usadas de forma complementaria, sin suplantar los clásicos reportajes fotográficos, dibujos o topografías, estos detalles no nos deberían preocupar; al menos no de momento. Sobre todo, si existe un registro más convencional que nos traslade la realidad de forma más directa y sin las pequeñas contras del $3 \mathrm{D}$ : falta de personal o medios para procesar la información es la principal, en nuestro caso. Más problemático y criticable sería basar nuestro sistema de documentación solo en estos modelos vertebrados por píxeles de información que, en algún punto, podrían estar modificados. Otro factor que induce a actuar de forma comprensiva con los nuevos programas es que no tardarán mucho en ser corregidos por nuevos diseños. La misma comprensión hay que aplicarla también a aquellos proyectos que aún no tengan ni los medios técnicos ni personales para realizar una sustitución inmediata de viejas herramientas por las nuevas que, desde luego, ya han demostrado ser mucho más efectivas en aquellos proyectos donde se han comparado (Olson et al. 2013). Mientras que un dibujo a mano alzada suele utilizar unas 50 mediciones por $\mathrm{m}^{2}$ un $3 \mathrm{D}$ emplea unos 500.00o puntos para construir su modelo (Benavides et al. 2016: 504). De todos modos, y hasta que los equipos arqueológicos puedan contar con el software y el hardware que permita asumir estas rutinas documentales diarias, el registro doble de 3D y dibujo-fotografías clásicos será la «vía intermedia» que nos queda mientras vamos superando esta transición.

Otro de los grandes avances, que corregiría muchos errores, sería la mencionada incorporación de los modelos 3D en paralelo a la propia excavación para así mejorar esta, su estrategia y su avance, así como las decisiones que se toman en el campo. Siempre hay un riesgo ya advertido, de que los procesos de revisión e interpretación se pospongan a fases posteriores a la excavación (De Reu et al. 2013: III8). Aunque estamos de acuerdo que sería deseable hacer la documentación 3D en paralelo, y posiblemente sea ese nuestro futuro, el problema está en disponer de equipo técnico suficiente como para desarrollar este ingente trabajo. Otro de los trabajos que, en nuestro caso, está pendiente es la elaboración de un discurso detallado con los pasos y procedimientos desarrollados por nuestro equipo a la hora de realizar los modelos 3D pues, en un futuro, será una información clave para todos aquellos que revisen nuestro archivo tridimensional y quieran solventar dudas o extraer más información (De Reu et al. 20I3: III8). 


\subsection{LA IMPRESIÓN 3D: PRIMERAS PRUEBAS}

Para rentabilizar este pequeño dossier de archivos 3D también se pensó en imprimir parte de nuestros materiales para ver los resultados. Fruto de ese interés, y gracias a apoyos y colaboraciones desinteresadas, uno de los modelos del sondeo 2 se pudo imprimir en 20I7. El primer prototipo tridimensional del vuelo del dron de 2016 también estaba disponible en ese momento, mostrando una visión completa de la masa tumular, incluidos los dos sondeos practicados en el megalito. Contar con este material incentivó una colaboración con la Cátedra Medialab de la Universidad de Oviedo, que había adquirido varias impresoras 3D, para elaborar una maqueta del yacimiento a una escala lo suficientemente expresiva que permitiera su exhibición pública. Aunque a lo largo de 2019-2020 ya habíamos avanzado bastante en la propuesta este proyecto quedó finalmente inconcluso. Los primeros intentos son sin duda muy preliminares y necesitarán de mejoras si hay que inscribirlos en un discurso expositivo, aunque ya son lo suficientemente expresivos de las posibilidades de armar maquetas sencillas a partir de las fotogrametrías (Figura I3).

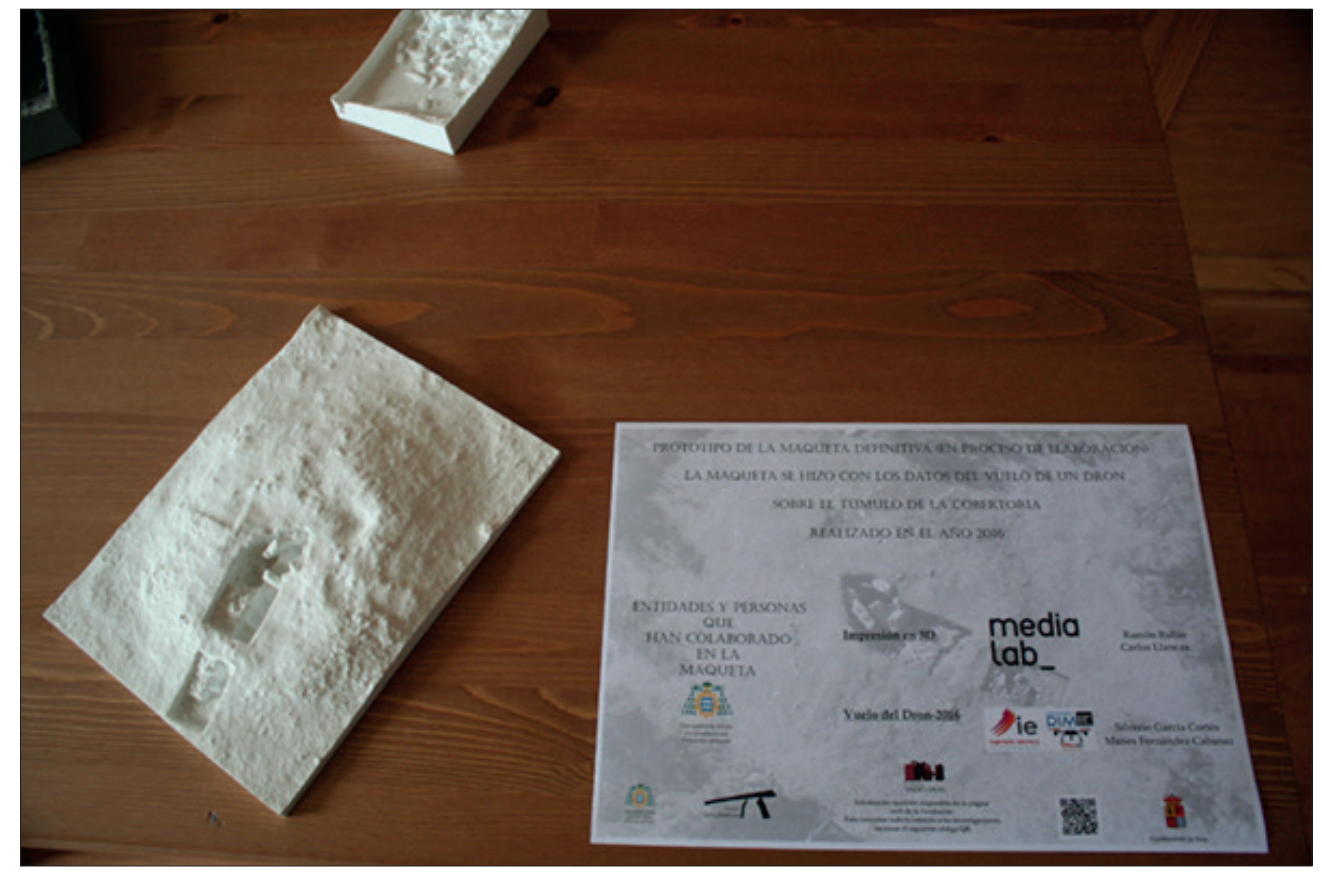

FIGURA 13. IMAGEN CON LAS MAQUETAS IMPRESAS, AHORA CUSTODIADAS EN LA EXPOSICIÓN TEMPORAL ALOJADA EN LA ESCUELA DE NIÑOS DE MALLECINA, POR LA ASOCIACIÓN DE VECINOS DE SAN PEDRO DE MALLECINA

\subsection{ACTIVIDADES ACADÉMICAS DESARROLLADAS CON LOS MATERIALES DIGITALES DEL PROYECTO}

Durante todo este proceso, largo y sinuoso por la necesidad de más financiación o de más tejido colaborativo, surgieron también posibilidades académicas. Nuestro punto de partida era un conjunto de modelos del sondeo 2 (seis diferentes), montados 
por los investigadores del equipo, y que permitieron a uno de los aquí firmantes, por entonces alumno de grado y colaborador durante varios veranos en las campañas de excavación, utilizar esta fuente y aplicarla a su Trabajo Fin de Grado (TFG) durante el curso académico 20I7/I8 de la Universidad de Oviedo (grado en Historia). El objetivo del TFG era aplicar la fotogrametría digital a un yacimiento prehistórico con el objetivo de desarrollar nuevas aportaciones a la difusión del patrimonio cultural. Todo ello fue posible gracias a un proceso formativo en aplicaciones informáticas de interés para el mundo tridimensional, así como a la lectura de publicaciones. En este último caso la bibliografía estaba ofreciendo no solo un buen marco teórico, sino también ejemplos que pudieran ser aplicados a nuestro caso concreto.

El hecho de que el TFG tuviera también una parte práctica permitió realizar una tarea que teníamos pendiente en el proyecto: el ensamblaje de los modelos ya disponibles en Blender lo que permitió crear dos columnas, de seis modelos cada una, del sondeo 2 de la excavación. Cada columna representa una propuesta diferente de recorrido por los mismos seis 3D. La primera genera un recorrido vertical, a modo de ascensor, por la excavación: desde el primer modelo, que representa el inicio de los trabajos (capas iniciales y superficiales). De ahí hasta el sexto y último, situado en la base de la columna, donde se visualizan los últimos horizontes. La segunda, aunque presenta también los sondeos en vertical, igual que la primera, la columna va rotando alrededor del 3 D y lleva incluida una animación muy dinámica en el paso de un modelo a otro.

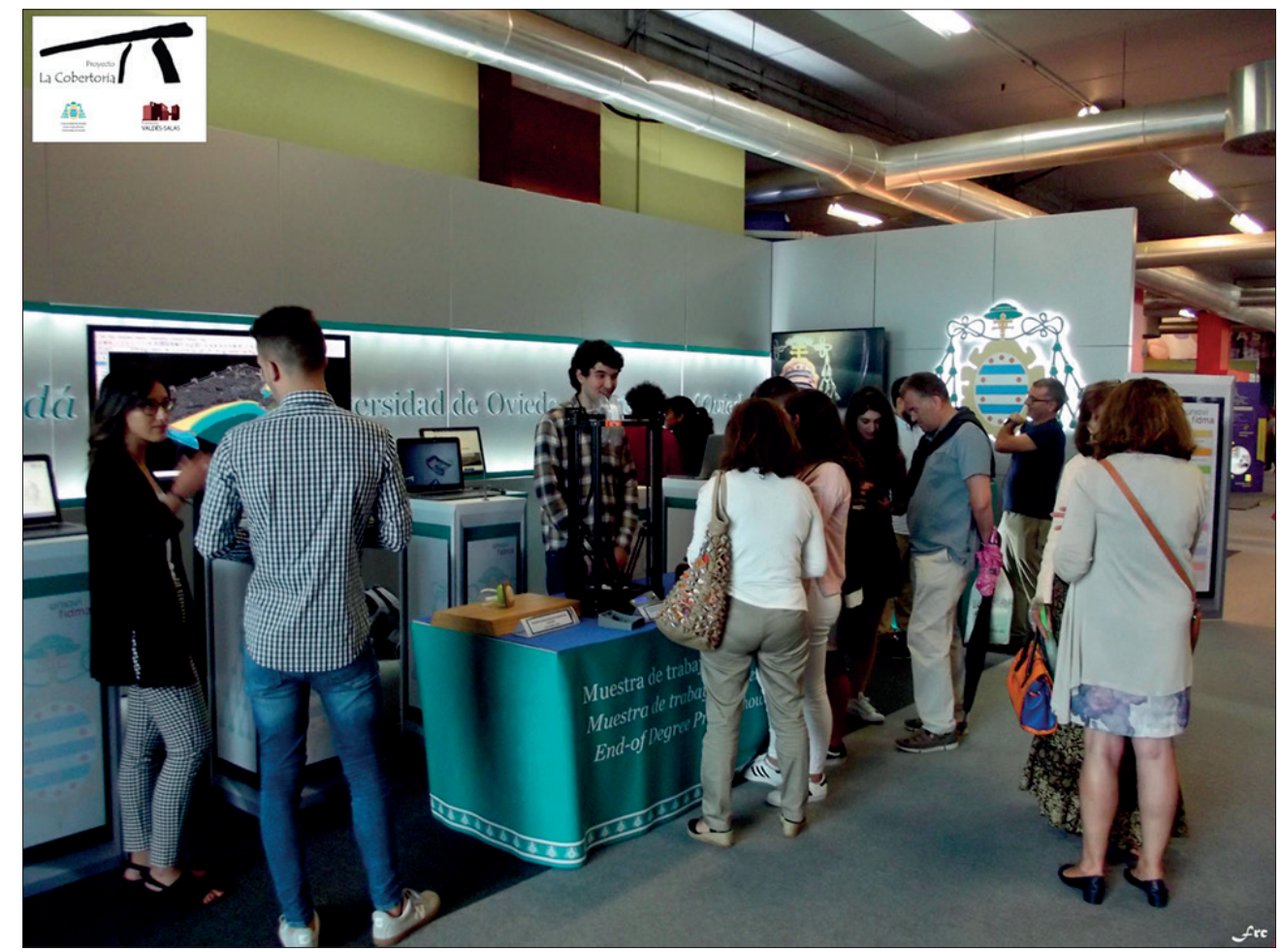

FIGURA 14. IMPRESIÓN DE LOS MODELOS TRIDIMENSIONALES DE LA COBERTORIA EN EL STAND DE LA UNIVERSIDAD DE OVIEDO, DURANTE LA FERIA DE MUESTRAS DE ASTURIAS 2018 (MESA DEL CENTRO DE LA IMAGEN) 
El trabajo fue presentado a la convocatoria de premios de Cátedra de Emprendimiento de la Fundación Universidad de Oviedo, en su convocatoria 20I7/18 para la difusión de trabajos fin de grado y máster, y resultó de los pocos premiados en la rama de Humanidades. Por ello, y como parte de los premiados, el ahora egresado fue invitado a participar en el stand de la Universidad de Oviedo, durante la Feria Internacional de Muestras de Asturias del año 20I8. La colaboración de nuestro proyecto con el Medialab permitió que mostrásemos, en el stand de la institución académica, la impresión in situ de uno de los modelos 3D de la Cobertoria que estábamos preparando (Figura I4).

\section{CONCLUSIONES}

La información presentada a lo largo del texto muestra claramente los aspectos positivos de lo tridimensional, sin eludir la parte negativa que puedan tener. No tenemos duda, no obstante, que programas y plataformas web irán mejorando, lo que permitirá una cada vez mayor aplicación al campo de la arqueología prehistórica. Para que esto ocurra, sin embargo, es necesario que las herramientas se vayan generalizando y que haya un mayor uso de las mismas. La propuesta aquí formulada se asienta en el valor que tiene poder contar con modelos tridimensionales como una parte más del registro arqueológico, al proveernos de datos empíricos fiables, de fácil consulta y que acumulan muchos datos, permitiendo también una posterior edición de esos constructos tridimensionales. El traslado de fragmentos de nuestras excavaciones a tres dimensiones, se nutrirá de diversos dispositivos que están en continua mejora; especialmente del uso de las gafas $3 \mathrm{D}$. La inversión constante en este sector facilitará la llegada de más aplicaciones que estimularán ediciones fáciles y rápidas de la información. El paso del tiempo y la evolución propia del método arqueológico irá pasando por su tamiz cada una de las herramientas, dejándonos con las más eficaces. Todo parece indicar que ahora se inicia una etapa donde se irán solapando distintos modos de trabajar y de recabar datos. La tendencia más lógica (como ocurre en cualquier avance tecnológico) será que se acaben imponiendo, tras un tiempo de convivencia, los medios más completos y rápidos. Por ello, y especialmente en este tiempo que ejerce de bisagra, es clave que empecemos ya a combinar registros, aunque los más modernos no sean perfectos ni aplicables en todo momento. Conociendo la ácida actitud de la historiografía arqueológica nos aventuramos a presuponer que aquellas excavaciones que no atesoren esta doble documentación correrán en el futuro el riesgo de ser acusadas de no haber integrado, en la medida de sus posibilidades, una técnica muy económica que estaba salvando más datos para la causa arqueológica. Mucho más cuando la necesidad de un registro multidimensional ya se ha formulado de forma clara y contundente, alegando la mayor calidad de la información que aporta: las formas de lo excavado, sus mejores visualizaciones, o que aporte tantos datos que no solo sea útil a las investigaciones actuales, sino que a buen seguro lo sea también para estudios futuros (De Reu et al. 2013: IIO9).

Ya es una realidad que gracias a esta nueva revolución tecnológica de nuestra disciplina veremos los yacimientos en tres dimensiones y los visitaremos sin estar 
siquiera pisando sobre ellos. Todo ello deberíamos intentar poder hacerlo, desde luego, con esa ciencia cada vez más tecnificada, aunque esperemos que, como dice Brian Fagan, no nos «hayamos especializado tanto que exista la tendencia de olvidarnos de las personas» (2018: 329).

\section{Agradecimientos}

Nuestro primer agradecimiento va dirigido a la Fundación Valdés-Salas y la Fundación Banco Sabadell, junto con el Ayuntamiento de Salas, pues sin el apoyo y colaboración de estas instituciones el proyecto no hubiera sido posible. También la gratitud hacia todos los colaboradores que a lo largo de distintos años participaron con especial interés y dedicación en el proyecto de la Cobertoria. Entre ellos es necesario destacar a dos personas que, gracias a dos becas, mantuvieron un vínculo académico más estrecho, ayudándonos con el registro documental generado estos años: son Francisco Lara Piñera y Jesús Fernández López. Los trabajos desarrollados en la Cobertoria no habrían sido posibles sin los permisos pertinentes de la propietaria de la finca, doña Margarita González García y sus familiares, a quienes queremos agradecer aquí todas las facilidades que nos han dado siempre. Desde el pueblo de Salas el cariño y la acogida ha sido siempre magnífica, y no solo desde lo institucional, también en lo humano: Quico (\&cía), Noemí (y Ana) o Ángeles formaron parte de nuestra vida diaria en Salas y son ya inolvidables para nosotros. Desde el colegio o el instituto Enedina y José Ignacio, junto con Cristina (Ayto. de Salas), todo el taller de infancia y el resto de directores de ambos centros resultaron también fundamentales para que las actividades escolares se pudieran llevar a cabo.

La Cátedra Medialab colaboró de forma desinteresada en la divulgación de resultados, así como imprimiendo varios modelos del sondeo 2 de nuestra excavación. Por tanto, nuestro débito personal con Ramón Rubio y Carlos Llaneza por las facilidades dadas en las distintas colaboraciones con ellos.

Finalmente, los Ayudantes doctores del Departamento de Historia Carla Rubiera Cancelas y Juan Díaz Álvarez se enfrentaron al tedioso, aunque también divertido, proceso de grabación de las voces que transmiten los textos de nuestras visitas virtuales y de las aproximaciones en vídeo. Por ello también nuestra mayor gratitud, al ser colaboraciones desinteresadas de las que hacen verdadera Universidad. 


\section{BIBLIOGRAFÍA}

Agisoft 20i6: Photoscan [online] http://www.agisoft.ru/products/photoscan [consult: 20I6].

AZUMA, R. T. I997: «A Survey of Augmented Reality». Teleoperators and Virtual Environments 6(4): $355-385$.

BenAvides, J. A., Esquivel, F.J. y Esquivel, J. A. 20I5: «Nuevas aportaciones al estudio métrico y geométrico del dolmen de Viera (Antequera, Málaga)». Menga. Revista de Prehistoria de Andalucía 6. Crónica, I0: 20I-208.

Benavides, J. A., Aranda, G., Sánchez, M., Alarcón, E., Fernández, S., Lozano, A. y EsQuivel, J. A. 20I6: «3D modelling in archaeology: the application of Structure from Motion methods to the study of the megalithic necropolis of Panoria (Granada, Spain)». Journal of Archaeological Science: Reports I0: 495-506. https://doi.org/IO.IOI6/j. jasrep.2016.II.022

Blas, M. Á. de I978: «El Cantón y Penausén I. Noticias sobre las excavaciones de dos megalitos asturianos», BIDEA 93-94: 323-333.

Blas, M. Á. de I980: «El megalito de Penausén I (Salas, Asturias)». Noticiario Arqueológico hispánico 9: 67-88.

Blas, M. Á. de 1983: La Prehistoria reciente en Asturias. Estudios de Arqueología asturiana $n^{o}$ I. Fundación pública de cuevas y yacimientos prehistóricos de Asturias. Oviedo.

Blas, M. Á. de 2008: «La plenitud de la arquitectura megalítica». En J. Rodríguez (Coord.): La Prehistoria en Asturias. Un legado artístico único en el mundo. Oviedo: 525-528.

Berggren, A., Dell'unto, N., Forte, M., Haddow, S., Hodder, I., Issavi, J. Lercari, N., Mazzucato, C., Mickel, A., Y TAylor, J. 2015: «Revisiting reflexive archaeology at Çatalhöyük: integrating digital and 3D technologies at the trowel's Edge». Antiquity 89, (344): 433-448. https://doi.org/IO.I5I84/aqy.20I4.43

BouzA, F. I965: «Túmulos dolménicos y círculos líticos de la sierra de Pumarín». Boletín del Real Instituto de Estudios Asturianos, 54: 4-I6.

Burke, H. Y Smith, C. 2004. The archaeologist's field handbook. Allen\&Unwin. Sidney.

CARO, J. L. Y HANSEN, S. 2015: «De la fotogrametría a la difusión del patrimonio arqueológico mediante game engines: Menga un caso de estudio». Virtual Archaeology Review 6 (I2): 58-68. https://doi.org/10.4995/var.2015.4159

CRAIG, A. B. 20I3: Understanding augmented reality: Concepts and applications. Morgan Kaufmann. Amsterdam.

Dell' Unto, N. Landeschi, G., Apel, J. y Poggi, G. 20I7: «4D recording at the trowel's edge: using three-dimensional simulation platforms to support field interpretation». Journal of Archaeological Science: Reports I2: 632-645. https://doi.org/IO.IOI6/j.jasrep.20I7.03.0II

De Reu, J., Plets, G., Verhoeven, G., De Smedt, Ph., Bats, M., Cherretté, B., De Maeyer, W., Deconynck, J., Herremans, D., Laloo, P., Meirvene, M. y De ClercQ, W. 20i3: «Towards a three-dimensional cost-effective registration of the archaeological heritage». Journal of Archaeological Science 40: IIO8-II2I. https://doi.org/IO.IOI6/j.jas.20I2.08.040

DíAz, F., JimÉnez, J., BARredA, A., Asensi, B. y Hervás, J. 20I5: «Modelos 3d para la generación de patrimonio virtual». Virtual Archaeology Review 6,(I2): 29-37. https://doi.org/I0.4995/ var.2015.4I50

Doneus, M., Verhoeven, G., Fera, M., Briese, C., Kucera, M., y Neubauer, W., 2oit: «From deposit to point cloud e a study of low-cost computer vision approaches for the 
straightforward documentation of archaeological excavations». En XXIIIrd International CIPA Symposium vol. 6. Prague.

Esclapés, J., Tejerina, D., Bolufer, J., y Esquembre, M. A. 20I3: «Sistema de Realidad Aumentada para la musealización de yacimientos arqueológicos». Virtual Archaeology Review 4(9): 42-47. https://doi.org/I0.4995/var.20I3.4246

FÁbregas, R. y VILASECO, X. I. 2004: «El megalitismo gallego a inicios del siglo XX. En Tema monográfico: los enterramientos en la Península Ibérica durante la Prehistoria Reciente». Mainake, 26: 63-87.

FAGAN, B. 20I8: Breve Historia de la Arqueología. Biblioteca nueva. Madrid.

FrIERA, M. 20I6: «Los «Anales de la Universidad de Oviedo» (I902-I9II;I937-I950). Primera época». Diálogos jurídicos: anuario de la Facultad de Derecho de la Universidad de Oviedo I: II9-I83.

GonZÁLeZ, J. M. I973: «Recuento de los túmulos sepulcrales megalíticos de Asturias». Archivum XXIII: 5-42.

LERCARI, N. 20I7: «3D visualization and reflexive archaeology: a virtual reconstruction of Çatalhöyük history houses». Digital Applications in Archaeology and Cultural Heritage 6: IO-I7. https://doi.org/I0.I0I6/j.daach.2017.03.00I

LÓPEz-Romero, E. 20I4: «Out of the box': exploring the 3D modelling potential of ancient image archives». Virtual Archaeology Review Io (5): 107-II6. https://doi.org/I0.4995/ var.20I4.4224

López-Romero, E., Gülmil-Fariña, A., MaÑana, P., y Otero, C. 20I5: «Ocupación humana y monumentalidad durante la Prehistoria Reciente en el islote de Guidoiro Areoso (Ría de Arousa, Pontevedra): investigaciones en el marco de las dinámicas litorales atlánticas actuales». Trabajos de Prehistoria 72, (2): 353-37I. https://doi.org/I0.3989/tp.2015.12159

López-Romero, E., Daire, M.Y., MaÑana, P., y Quesnel, L. 20I5b: «Le tumulus de Kervingar (Plouarzel, Finistère): un regard nouveau sur les débuts de la recherche archéologique d'après-guerre en Bretagne». Revue archéologique de l'Ouest, 32: II3-I28. https://doi.

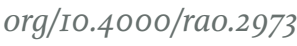

López-Romero, E., Mañana, P., Güımil-Fariña, A., Y Daire, M. Y. 20I6: «Archaeology and coastal erosion: monitoring change through $3 \mathrm{D}$ digital techniques». Proceedings of the XVII UISPP World Congress. Burgos.

MañanA, P. 2003: «Vida y muerte de los megalitos. ¿Se abandonan los túmulos?». EraArqueología. Revista de divulgação de estudos arqueológicos, 5: I64-177.

MAÑANA, P. 2005: «Túmulo 5 de Forno dos Mouros (Ortigueira, A Coruña). Primeiros resultados». Cuaderno de Estudios Gallegos, LII(II8): 39-79. https://doi.org/I0.3989/ceg.2005.152.iII8

Olson, B., Placchetti, R., Quartermaine, J. y Killebrew, A. 20I3: «The Tel Akko Total Archaeology Project (Akko, Israel): Assessing the suitability of multi-scale 3D field recording in archaeology». Journal of Field Archaeology 38 (3): 244-262. https://doi.org/IO .II79/0093469013Z.00000000056

Orlandi, M., Zambruno, S., y VAzZana, A. 20I4: «Tecnologia, Beni Culturali e Turismo: I Tour Virtuali (Virtual Tours) come strumento per una corretta comunicazione dei Beni Culturali». Storia e Futuro, 34.

Remondino, F. y Rizzi, A. 20I0: «Reality-based 3D documentation of natural and cultural heritage sites-techniques, problems and examples». Applied Geomatics 2(3): 85-Ioo. https:// doi.org/10.1007/SI2518-010-0025-X

Rodríguez, V. I992: «Carta arqueológica del concejo de Salas. Enero-Octubre, I989». Excavaciones arqueológicas en Asturias, 2 (1987-1990). 
R. Del Cueto, F. y Blas, M. Á. de 20I8: «Investigaciones iniciales en el megalito de la Cobertoria, en el paraje de la Campa San Juan (Mallecina, Salas)». Excavaciones arqueológicas en Asturias, 8 (2013-16), I7I-182.

R. Del Cueto, F. y Busto, M. 2020: «La construcción secular de un espacio funerario mediante distintas arquitecturas monumentales: primeras consideraciones tras las investigaciones en la Cobertoria (Salas, Asturias)». Lucentum, 39, 53-72. https://doi. org/IO.I4I98/LVCENTVM2020.39.03

R. Del Cueto, F. y CARrero, M. 202I: «Límites y posibilidades de los análisis LiDAR aplicados al megalitismo asturiano. Revisión de cuatro conjuntos tumulares prehistóricos en el concejo de Salas (España)». Veleia, 38, 9-3I, https://doi.org/Io.I387/veleia.2I455

TEJEDOR, C. 20I4: «Reconstruyendo 'biografías megalíticas': algunos ejemplos de alteraciones estructurales en monumentos megalíticos del valle del Duero/Douro». En Honrado, J.; Brezmes, M.; Tejeiro, A.; Rodríguez, O. (coords.): Investigaciones Arqueológicas en el valle del Duero: Del Neolítico a la Antigüedad Tardía. Il Jornadas de Jóvenes Investigadores del valle del Duero. Ed. Glyphos. Valladolid: 67-86.

Verhoeven, G. 20II: «Taking computer vision aloft-Archaeological Three-dimensional reconstructions from aerial photographs with Photoscan». Archaeological Prospection 18: 67-73. https://doi.org/I0.I002/arp.399 